\title{
Model-Data Comparisons for Titan's Nightside Ionosphere
}

T. E. Cravens (1), I. P. Robertson (1), J. H. Waite Jr. (2), R. V. Yelle (3), V. Vuitton (3,6), A. J. Coates (4), J.-E. Wahlund (5), K. Agren (5), M. S. Richard (1), V. De La Haye (2), A.

Wellbrock (4), F. M. Neubauer (7)

1. Department of Physics and Astronomy, Malott Hall, 1251 Wescoe Hall Dr., University of Kansas, Lawrence, KS 66045, USA

2. Southwest Research Institute, P.O. Drawer 28510, San Antonio, TX 78228-0510, USA

3. Lunar and Planetary Laboratory, University of Arizona, 1629 E. University Blvd., Tucson, AZ 85721-0092, USA

4. University College London, Mullard Space Science Laboratory, Holmbury St. Mary, Dorking, Surrey RH5 6NT, UK

5. Swedish Institute of Space Physics, Uppsala Division, Box 537, SE-751 21 Uppsala, Sweden

6. Now at Laboratoire de Planétologie de Grenoble, Grenoble, France

7. Institut für Geophysik und Meteorologie, Universität zu Köln, Cologne, Germany

\begin{abstract}
Solar and x-ray radiation and energetic plasma from Saturn's magnetosphere interact with the upper atmosphere producing an ionosphere at Titan. The highly coupled ionosphere and upper atmosphere system mediates the interaction between Titan and the external environment. A model of Titan's nightside ionosphere will be described and the results compared with data from the Ion and Neutral Mass Spectrometer (INMS) and the Langmuir probe (LP) part of the Radio and Plasma Wave (RPWS) experiment for the T5 and T21 nightside encounters of the Cassini Orbiter with Titan. Electron impact ionization associated with the precipitation of magnetospheric electrons into the upper atmosphere is assumed to be the source of the nightside ionosphere, at least for altitudes above $1000 \mathrm{~km}$. Magnetospheric electron fluxes measured by the Cassini electron spectrometer (CAPS ELS) are used as an input for the model. The model is used to interpret the observed composition and structure of the T5 and T21 ionospheres. The densities of many ion species (e.g., $\mathrm{CH}_{5}{ }^{+}$and $\mathrm{C}_{2} \mathrm{H}_{5}{ }^{+}$) measured during T5 exhibit temporal and/or spatial variations apparently associated with variations in the fluxes of energetic electrons that precipitate into the atmosphere from Saturn's magnetosphere.
\end{abstract}

\section{Introduction}

Solar radiation and energetic plasma from Saturn's magnetosphere ionizes the neutral molecules in Titan's ionosphere, creating an ionosphere at altitudes above about $400 \mathrm{~km}$ (Bird et al. 1997; Wahlund et al. 2005; Young et al. 2005; Keller et al. 1992; Gan et al. 1992; Cravens et al. 2004, 2005; Galand et al. 1999; Banaskiewicz et al. 2000; Molina-Cuberos et al. 2001; Lilensten et al. 2005a; Agren et al. 2007; Cravens et al. 2008, Kliore et al., 2008). Titan's neutral atmosphere consists mainly of molecular nitrogen and methane but the relatively minor amounts of many hydrocarbon and nitrogen-bearing species play an important role in the upper atmosphere and ionosphere (Waite et al. 2005; Vuitton et al. 2006, 2007; Fox and Yelle 1997; 
Keller et al. 1998; Waite et al. 2007). The first in situ measurements (electron densities and temperatures) of Titan's ionosphere were made during the October 2004 Ta encounter of the Cassini Orbiter by the Langmuir Probe (LP) part of the Radio Wave and Plasma Wave (RPWS) experiment (or RPWS/LP) (Wahlund et al. 2005). Magnetic fields in the ionosphere were measured by the magnetometer experiment (Backes et al. 2005).

The Ta Cassini data plus modeling demonstrated that the observed ionosphere on the dayside could largely be explained by photoionization by solar radiation (Galand et al. 2006; Cravens et al. 2005). The current paper will focus though on the ionosphere on the nightside where the solar source obviously cannot operate. Impact ionization by energetic electrons transported along magnetic field lines from Saturn's outer magnetosphere has long been thought to be an important ionization source (cf. Atreya 1986; Gan et al. 1992; Cravens et al. 2008 and references therein) and it has also been suggested as a source of the ionosphere observed by Cassini during T5 (Cravens et al. 2006; Agren et al. 2007). Cravens et al. (2008) also suggested that precipitation of energetic protons and oxygen ions from Saturn's magnetosphere into the atmosphere is an important source at lower altitudes $(\approx 500-800 \mathrm{~km})$ and might explain the ionosphere observed at these altitudes by the Cassini Radio Science (RSS) experiment (Kliore et al. 2008).

The first composition measurements in Titan's ionosphere were made by the Cassini Ion and Neutral Mass Spectrometer (INMS) during the outbound leg of the T5 pass in April 2005 (Cravens et al. 2006). The spacecraft remained deep on the nightside (i.e., solar zenith angles of $\left.\approx 135^{\circ}\right)$ during this time. The RPWS/LP experiment measured a substantial electron density $\left(\mathrm{n}_{\mathrm{e}}\right.$ $\approx 1000 \mathrm{~cm}^{-3}$ ) on both the inbound and outbound legs of T5 (Agren et al. 2007); for the latter, the electron densities measured by RPWS/LP and the total ion densities measured by the INMS were in good agreement for altitudes below about $1500 \mathrm{~km}$ (Cravens et al. 2005). The INMS is able to measure ion species with mass numbers up to 99 , and the T5 data revealed species with substantial densities for about 40 - 50 species. A rich and complex ion-neutral chemistry scheme was expected prior to the Cassini mission (cf. Keller et al. 1998; Fox and Yelle 1997; Wilson and Atreya 2004; Anicich et al. 2004) and the T5 INMS data did not disappoint. Many predicted species were indeed present (e.g., $\mathrm{C}_{2} \mathrm{H}_{5}{ }^{+}, \mathrm{CH}_{5}{ }^{+}, \mathrm{C}_{3} \mathrm{H}_{5}{ }^{+}, \ldots$ ) but the existence of other species was not predicted at any significant abundance by pre-Cassini models (e.g., Keller et al . 1998; Fox and Yelle 1997; Wilson and Atreya 2004; Coates et al. 2007a), including species at $\mathrm{m}$ $=18,30,54$, and 66. Subsequent mass spectra measured during dayside Titan passes by the INMS have confirmed that relative ion composition on the day and nightsides are similar (paper in preparation).

Most of the previously unexplained "new" ion species were interpreted by Vuitton et al. $(2006,2007)$ as being due to reaction of major ion species with a variety of neutral nitrogenbearing species whose abundances were low enough such that they were not measurable by the INMS (in its neutral mode "CSN" mode). For example, both Vuitton et al. (2006) and Cravens et al. (2006) suggested that the mass 18 species was $\mathrm{NH}_{4}{ }^{+}--$formed by the reaction of major ion species with ammonia. And Vuitton et al. (2006) suggested that mass 30 was $\mathrm{CH}_{2} \mathrm{NH}_{2}{ }^{+}$ produced by reaction of $\mathrm{HCNH}^{+}$with $\mathrm{CH}_{2} \mathrm{NH}$. Vuitton et al. (2007) explained mass 66 as $\mathrm{C}_{2} \mathrm{H}_{3} \mathrm{CNH}^{+}$-- produced by reaction of $\mathrm{HCNH}^{+}$with the nitrile species $\mathrm{C}_{2} \mathrm{H}_{3} \mathrm{CN}$. The ion chemistry for heavier species may have significant implications for aerosol formation lower in the atmosphere (e.g., Waite et al. 2007). The Vuitton et al. papers focused on the chemical aspects of the T5 neutral and ion composition data. For the current paper we adopt most of the 
chemistry presented by Vuitton et al. and concentrate on explaining the structure and source(s) of the T5 (and T21) nightside ionosphere.

The chemical part of the model for the current paper only includes chemistry for ion species. That is, purely neutral chemistry was not included and neutral abundances for both major and minor species were adopted from INMS data or from other papers referenced later. A full understanding of the chemistry of Titan's upper atmosphere requires a coupled ion and neutral chemical model such as the pre-Cassini model described by Wilson and Atreya (2004) and the post-Cassini model of De La Haye et al. (2008a).

Energetic electrons were observed in Saturn's outer magnetosphere by Voyager (Schardt et al. 1984) and by both the CAPS ELS (Coates et al. 2007b) and MIMI (Krimigis et al. 2005) instruments onboard Cassini. Cravens et al. (2006) suggested that incident electrons with a broad range of energies $(25 \mathrm{eV}-2000 \mathrm{keV})$ were needed to explain the ionospheric densities measured by the RPWS/LP and INMS during T5, and this has been confirmed by detailed calculations by Agren et al. (2007). Agren et al. pointed out that the electron fluxes observed by the CAPS ELS near Titan during the T5 pass exceeded by roughly a factor of ten the fluxes needed to produce the observed ionosphere. Agren et al. also described the general magnetospheric context of the T5 pass. The spacecraft closest approach and outbound leg (where the INMS made open source ion measurements) was approximately on the ramside of Titan with respect to the magnetospheric flow.

The current paper picks up where the Agren et al. (2007), Vuitton et al. (2006, 2007), and De La Haye et al. (2008a) papers leave off. De La Haye et al. (2008a) combine neutral and ionospheric chemistry in a one-dimensional model that accounts for horizontal variations as well as temporal variations via a rotation of Titan, assuming that the upper atmosphere rotates at the same rate as the solid body. The basic model components were described by Keller et al. (1992, 1998) and by Gan et al. (1992, 1993) (but with some improvements as discussed by Cravens et al. 2004). The current paper makes detailed model comparisons for a number of individual ion species measured by the INMS for T5 and T21. The current paper also investigates the temporal/vertical structure of Titan's nightside ionosphere in the context of the electron fluxes measured by CAPS. In particular, the paper will explore differences in ionospheric structures between "primary" ion species such as $\mathrm{CH}_{5}{ }^{+}$and more "chemically-processed" species, such as $\mathrm{HCNH}^{+}$. The paper will suggest that smaller-scale structure below about $1400 \mathrm{~km}$ can be explained by temporal and spatial variations in the incident energetic electron flux.

\section{Magnetospheric electrons as a source of Titan's ionosphere}

The electron gas in Saturn's outer magnetosphere is "hot" with typical thermal energies in the $100 \mathrm{eV}-1 \mathrm{keV}$ range (cf. Coates et al. 2007b; Rymes et al. 2007). Figure 1 shows an electron spectrum from the Cassini CAPS ELS experiment for the T5 time period. The several electron populations evident in this, and similar, electron spectrographs were discussed by Coates et al. (2007b), but we will point out a few relevant features here. During times near closest approach for T5 the CAPS ELS pointed approximately along the spacecraft ram direction and pitch angles very roughly near $90^{\circ}$ were sampled. The magnetospheric population can be located in the spectrographs near the beginning and end time periods. Substantial electron fluxes in the $100 \mathrm{eV}-2 \mathrm{keV}$ energy range are present with measurable fluxes persisting up to energies of several keV. The Cassini MIMI instrument observed electrons with energies of many tens of $\mathrm{keV}$ near T5 (Krimigis et al. 2005). When the spacecraft is sunlit the CAPS ELS observes spacecraft photoelectrons with energies less than about $5 \mathrm{eV}$, but for $\mathrm{T} 5$ this population 


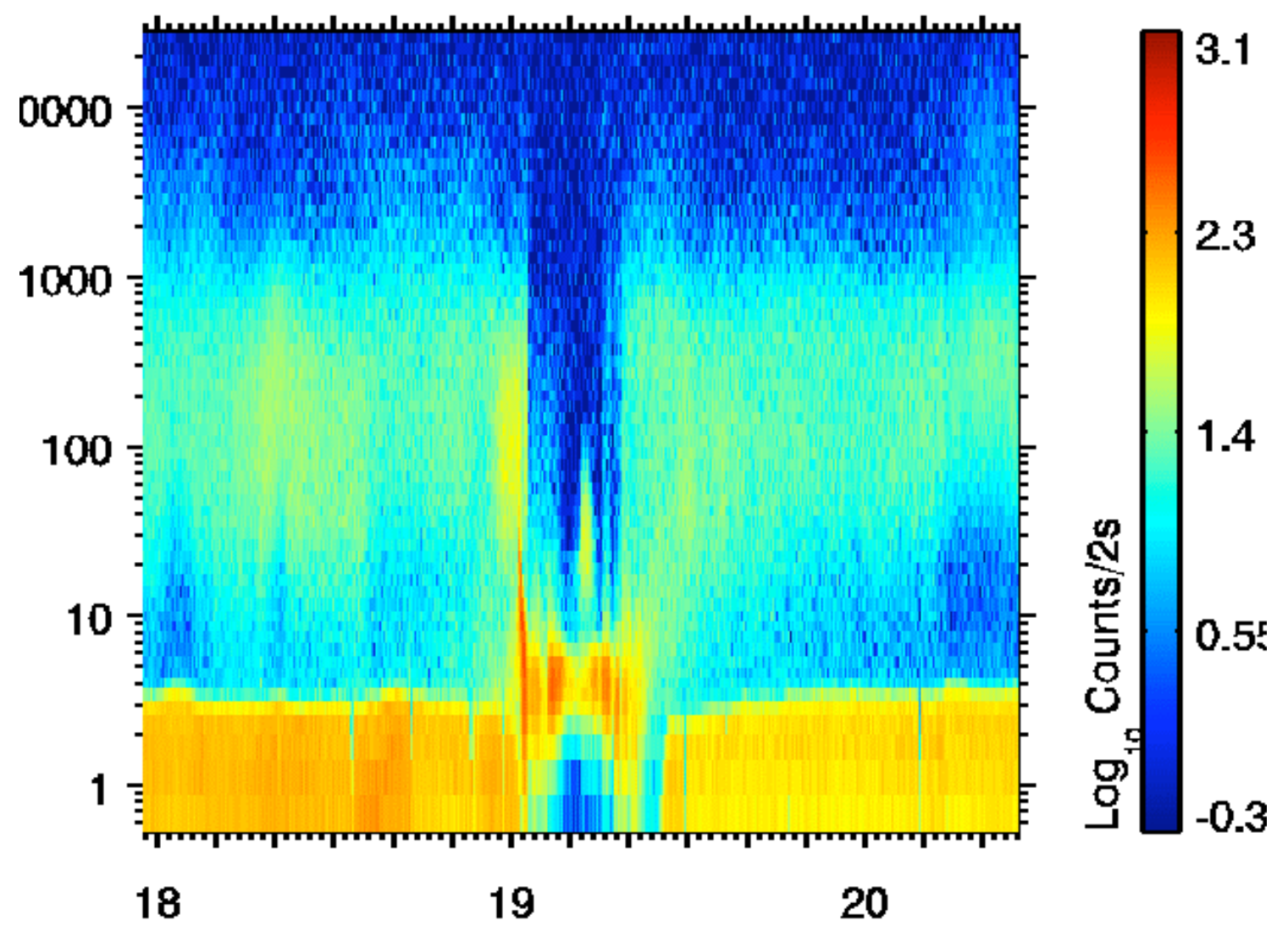

Figure 1. Energy-time spectrograph of suprathermal electron fluxes measured by the CAPS ELS instrument during the Cassini T5 encounter. Energy in $\mathrm{eV}$ is shown on the ordinate and time is shown on the abscissa. The flux levels are shown with the color scale in the figure.

disappeared when Cassini went through Titan's shadow in the time period near CA. The low energy electrons near CA are secondary electrons produced in the atmosphere by electron impact ionization of neutrals by the primary incident electrons. An interesting, but not obvious, feature in Figure 1 is the roughly 2 minute time variation in the secondary electron flux (most evident for energies of a few eV or less) seen by the CAPS ELS near CA. This time period corresponds to a distance along the spacecraft track of about $1000 \mathrm{~km}$.

The electron spectrum observed just outside Titan does not exhibit much variability. Figure 2 shows a sample flux versus energy plot very similar in shape to the one shown by Agren et al. (2007), but the CAPS ELS fluxes shown in Figure 2 are about a factor of 4 less than those shown by Agren et al. due to a recent recalibration of the instrumental geometric factor. T21 was another Titan encounter that took place on the nightside. The CAPS ELS spectra for Saturn's magnetosphere just outside Titan for T21 (not shown) were about 10 times less than for T5 and the typical energies were somewhat lower for T21. Unlike during T5, the CAPS ELS actuator was operating during T21 and the observed directional variations in the magnetospheric electron fluxes were less than a factor of 2 or so. 
Data obtained by the Voyager magnetometer for its encounter with Titan's magnetotail demonstrated that Saturn's magnetic field was strongly "draped" around Titan (cf. Neubauer 1984). A number of magnetohydrodynamic and hybrid models have been developed to explain the Titan interaction (e.g., Ledvina and Cravens 1998; Kabin et al. 1999; Ledvina et al. 2005). Cassini plasma and field data have greatly added to the database and have guided more recent modeling efforts (e.g., Backes et al. 2005; Ma et al. 2004, 2006, 2007; Modolo et al. 2007; Ledvina et al. 2005). The interaction of the external plasma flow with Titan is not simple and is affected by the characteristics of the external flow (which varies with time) and of the orientation of the external flow with respect to the direction to the Sun (due to the asymmetries this introduces in the ionization rate, and resulting plasma mass-loading rate). This topic is relevant to the current paper because the magnetic field topology affects the transport of magnetospheric electrons into the atmosphere and also affects the dynamics of the ionosphere. However, any detailed consideration of this topic is outside the scope of this paper. A few quite simple field geometries will be adopted for the current paper.

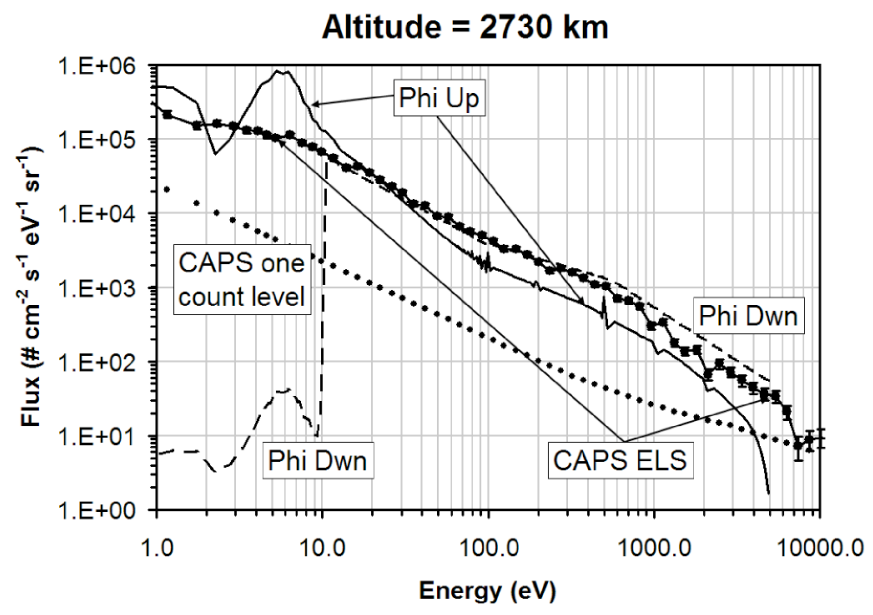

Figure 2. An electron flux versus energy spectrum measured by the CAPS ELS instrument for April 16, 2005, and 19:25 UT is shown with the line with filled circles with 1-sigma statistical error bars. This is a "typical" electron spectrum for the outer magnetosphere of Saturn in the vicinity of Titan near the time of the T5 Cassini encounter. The 1 count per second instrument "noise" level is also shown; fluxes less than this level have greater statistical uncertainty, yet due to averaging are still valid (see error bars). The dashed and solid lines are downward (Phi Dwn) and upward (Phi Up) electron fluxes from a theoretical model for an altitude of $2730 \mathrm{~km}$ (discussed in the text).

The magnetic field measured in Titan's ionosphere by the Cassini magnetometer (Backes et al. 2005) throughout the outbound portion of the T5 encounter was oriented at an angle of about $45^{\circ}$ with respect to the radial direction. The field strength in the ionosphere was about 5- $10 \mathrm{nT}$. This portion of the Cassini trajectory was roughly $50^{\circ}$ off from the nominal ram direction and took place at high latitudes. An accurate determination of electron transport requires a knowledge of the global field line topology, but field data along the spacecraft track alone cannot provide this topology (e.g., Galand et al., 2006). MHD-type modeling is also needed. For the current paper we will simply adopt 3 simple magnetic field configurations: (1) radial fields, (2) 
parabolic field lines with apex at the surface, and (3) parabolic field lines with apex at an altitude of $725 \mathrm{~km}$. The surface parabola is the preferred configuration because for this case the field orientation near an altitude of $1100 \mathrm{~km}$ is close to the measured orientation.

We need to calculate electron fluxes within the atmosphere in order to find ionization rates. Upward and downward suprathermal electron fluxes as functions of altitude and energy are calculated using a two-stream electron transport method, as described by Gan et al. $(1992,1993)$. Both elastic and inelastic collisions with molecular nitrogen and methane are taken into account as well as Coulomb collisions with thermal electrons. A key collision process is impact ionization of neutrals which produces secondary electrons according to known differential cross sections. Secondary electrons have energies ranging from zero up to a large fraction of the primary energy, but typical energies are a few $\mathrm{eV}$ up to tens of $\mathrm{eV}$. The electrons are allowed to go both directions along the field with a angular distribution assumed to be isotropic in each direction (fluxes: $\phi^{+}(\mathrm{E}, \mathrm{s})$ and $\phi^{-}(\mathrm{E}, \mathrm{s})$, where $\mathrm{E}$ is the electron energy and $\mathrm{s}$ is distance along the field which is a known function of altitude $\mathrm{z}$ ). A discrete energy grid was adopted with $\Delta \mathrm{E}=0.5$ $\mathrm{eV}$ at the lowest energies, increasing to $10 \mathrm{eV}$ at the code's highest energy of $5 \mathrm{keV}$.

The two-stream method was originally developed for terrestrial photoelectron transport (Nagy and Banks 1970) and we have previously used it to find photoelectron fluxes on the dayside of Titan (Cravens et al. 2004, 2005). In this case the suprathermal electrons are produced by photoionization of neutrals by solar photons (also see Galand et al. 2006). For the current paper, photoelectrons are not considered and instead magnetospheric electrons are introduced as a boundary condition on $\phi^{-}$at the "end" of the field line well outside the atmosphere. De La Haye et al. (2007a,b, 2008b) discussed an application of the two-stream method to the problem of how suprathermal neutrals, produced by exothermic ion and neutral chemistry, contribute to populating Titan's corona and neutral gas heating rates (and efficiencies) in Titan's upper atmosphere. De La Haye et al. (2008b) calculated local-time dependent heating rate profiles, and specified the contribution of magnetospheric electrons to neutral heating, taking into account the excitation of atmospheric molecules by electron impact, electron impact ionization and dissociation, and suprathermal electron heating. Many of the electron impact cross sections used in the current paper are presented by De La Haye et al. (2008b).

The magnetospheric electron fluxes measured by the CAPS ELS for T5 or for T21 (see Figures 1 and 2) are used as the boundary condition at the "top" of the atmosphere for the downward electron flux in our two-stream model (also see discussion in the Agren et al. 2007 paper). However, in order to exclude any possible spacecraft photoelectrons, we set the boundary flux to zero for energies less than $10 \mathrm{eV}$. The fluxes predicted by the model for energies less than $10 \mathrm{eV}$ are secondary electrons produced by impact ionization of atmospheric neutrals.

A neutral atmosphere model with densities of the major neutral species as a function of altitude is also needed for the two-stream model (Figure 3) and is described later. The twostream model also requires ionospheric "thermal" electron density and temperature profiles in order to determine suprathermal electron energy losses due to Coulomb collisions. We adopt RPWS/LP density and temperature values (Wahlund et al. 2005; Cravens et al. 2006; Agren et al. 2007). 


\section{T5B4 Select Neutral Densities}

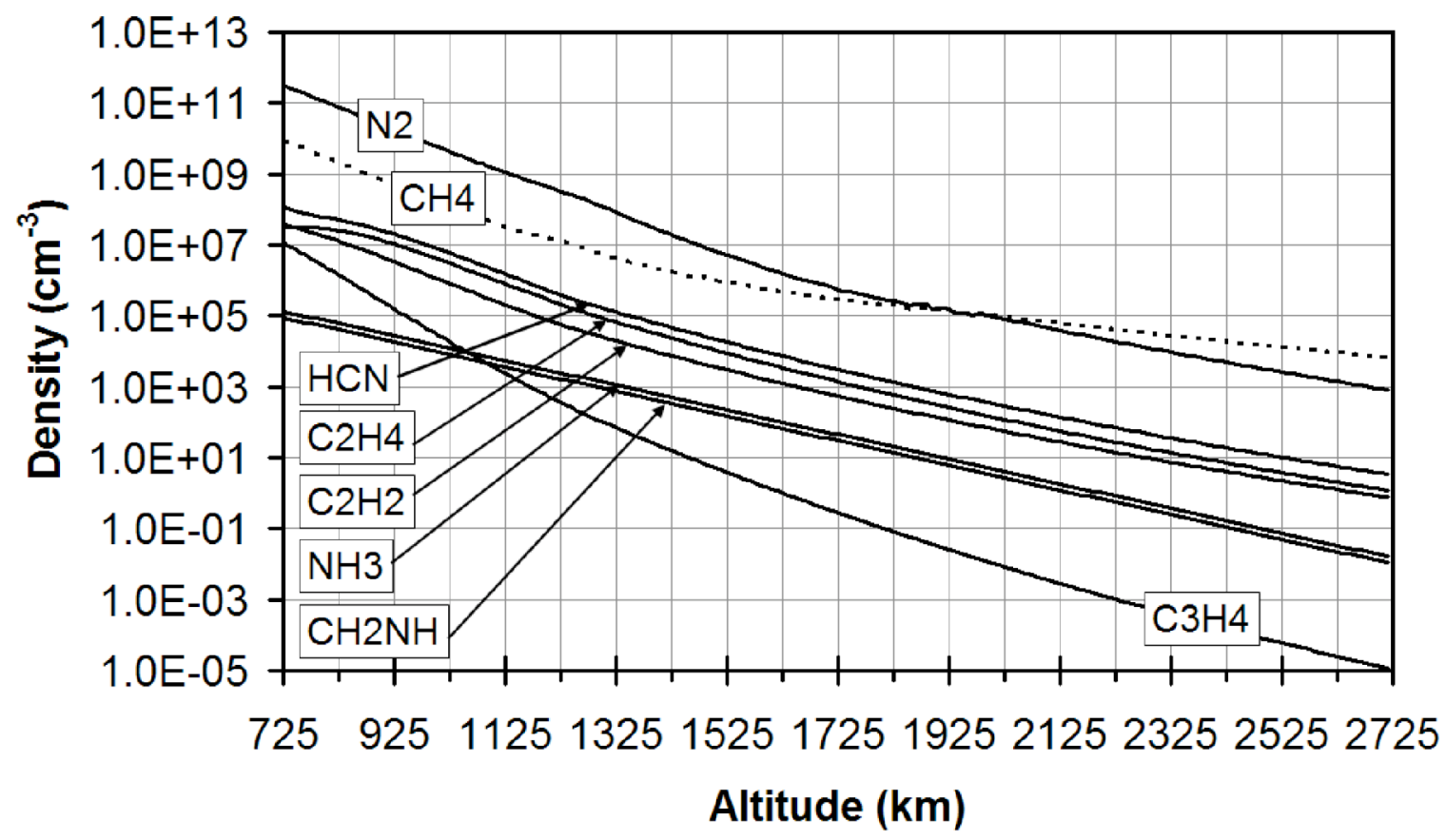

Figure 3. Density versus altitude profiles for several neutral species. The densities of molecular nitrogen and methane shown here were used for all the model calculations in this paper, but the minor neutral densities in this figure are just for the B4 case.

Figure 2 shows calculated electron fluxes near the top of the model atmosphere. The magnetic field line anchored at the surface (see above) was used for this case. The downward flux above $10 \mathrm{eV}$ is essentially the CAPS ELS flux. The upward flux at this altitude are backscattered electrons at higher energies and escaping secondary electrons (from electron impact ionization of neutrals by the precipitating "primary" electrons) below about $100 \mathrm{eV}$. Figure 4 shows calculated electron fluxes versus energy for T5 for an altitude well within the ionosphere $(1200 \mathrm{~km})$. The calculated electron fluxes at higher energies $(\mathrm{E}>100 \mathrm{eV})$ are dominated by degraded primaries, and at lower energies by secondary electrons. The electron spectrum measured by the CAPS ELS at this altitude is also shown. Note that the CAPS ELS electron flux is about a factor of $8-10$ lower than the model fluxes, suggesting that the actual boundary flux for the selected field lines should be reduced from the fluxes measured by CAPS in the nearby magnetosphere on field lines not attached to Saturn.

Overall, the model-data comparison is rather good, but there is one major caveat --- the incident (boundary) electron flux in the model (i.e., the magnetospheric spectrum measured by CAPS) must be reduced by a factor of about 8 to 10 in order to get agreement between the measured and calculated electron fluxes at $1200 \mathrm{~km}$. This caveat also holds for the comparison at other altitudes within the ionosphere (not shown) and is true regardless of which of the 3 magnetic field line configurations was adopted. Agren et al. also required a similar reduction factor of the incident magnetospheric electron flux in their modeling in order to get thermal 


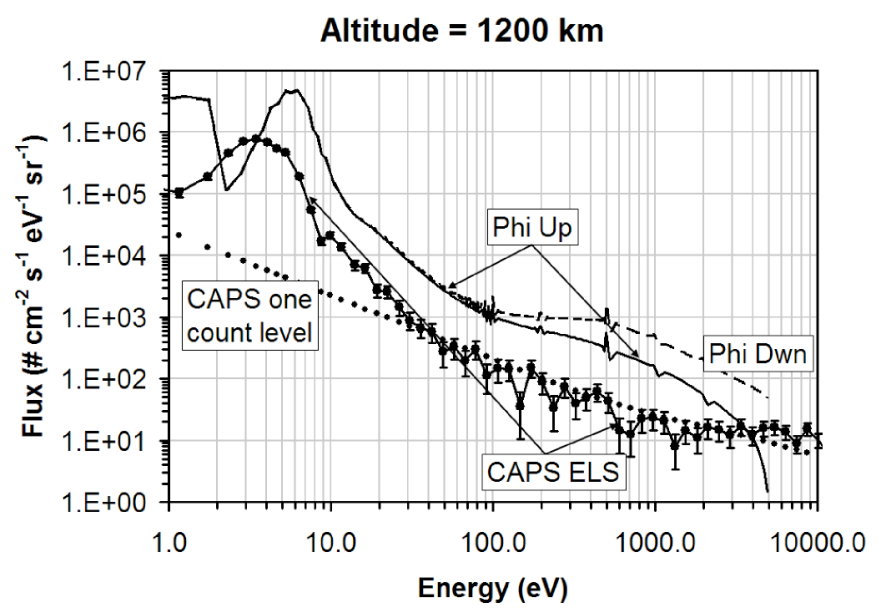

Figure 4. Calculated and measured electron fluxes versus energy are shown for an altitude of $1200 \mathrm{~km}$ in Titan's atmosphere. The boundary electron spectrum for the model calculation was the T5 profile shown in Figure 2.

ionospheric electron densities that matched densities measured by the Langmuir probe. However, the CAPS ELS fluxes they used were higher than the ones used in the current paper by about a factor of 4 due to a recent recalibration of the CAPS ELS geometric factor. If the Agren et al. calculations were repeated with the new CAPS ELS boundary fluxes they would only require a factor of 2.5 depletion, not 10, to reproduce their ionospheric density profiles. Nonetheless, some depletion of suprathermal electrons on field lines entering Titan's atmosphere is still required. Possible explanations for this depletion factor will be discussed later in the paper.

Note that our pre-Cassini two-stream calculations of the dayside photoelectron spectrum (Cravens et al. 2004) and recent (unpublished) calculations of the dayside suprathermal electron spectra for the Ta Cassini encounter agree well with spectra measured by the CAPS ELS instrument during Ta, both quantitatively and qualitatively. Both measured and calculated photoelectron spectra show the expected structure near $25 \mathrm{eV}$, associated with photoionization of neutrals by the solar HeII $30.4 \mathrm{~nm}$ line. Independent calculations of dayside suprathermal electron fluxes by Galand et al. (2006) show good agreement between theoretical fluxes and fluxes measured during Ta by the CAPS ELS. Dayside photoelectron flux calculations will need to be re-examined because it appears likely that the model fluxes will now be lower than the measured fluxes (after the CAPS ELS recalibration), and we are working on this now.

Models of the thermal ion and electron densities within any ionosphere require "primary" ion production rates associated with external sources such as photoionization by solar radiation, electron impact ionization, or energetic ion impact ionization (cf. Cravens et al. 2008). Ion production rates associated with suprathermal electron precipitation at a particular altitude are given by the integral over electron energy of the product of the electron flux with the ionization cross section and with the neutral density. Electron impact with $\mathrm{N}_{2}$ produces both $\mathrm{N}_{2}{ }^{+}$and $\mathrm{N}+$ ions (about $90 \%$ and $10 \%$, respectively) and impact with $\mathrm{CH}_{4}$ produces $\mathrm{CH}_{4}^{+}, \mathrm{CH}_{3}{ }^{+}, \mathrm{CH}_{2}{ }^{+}, \mathrm{CH}^{+}$, and $\mathrm{H}^{+}$ions. Ion production from some minor neutrals such as $\mathrm{C}_{2} \mathrm{H}_{6}$ and $\mathrm{HCN}$ was also included in our model, but these are not important. 
Figure 5 shows $\mathrm{N}_{2}^{+}$and $\mathrm{CH}_{4}^{+}$production rates versus altitude for both T5 and T21 from 2stream code runs for which the boundary conditions were the magnetospheric CAPS ELS spectra mentioned earlier. The production rates shown in the figure are reduced by a factor of 2.5 and are used as such in the chemical model. Production rates for other ion species were included in the chemical model, but are not shown. Ion production rates calculated for the T21 case are considerably smaller than the T5 rates, as expected since the magnetospheric electron fluxes observed by CAPS near Titan are smaller for T21 (not shown) than for T5. Figure 5 indicates

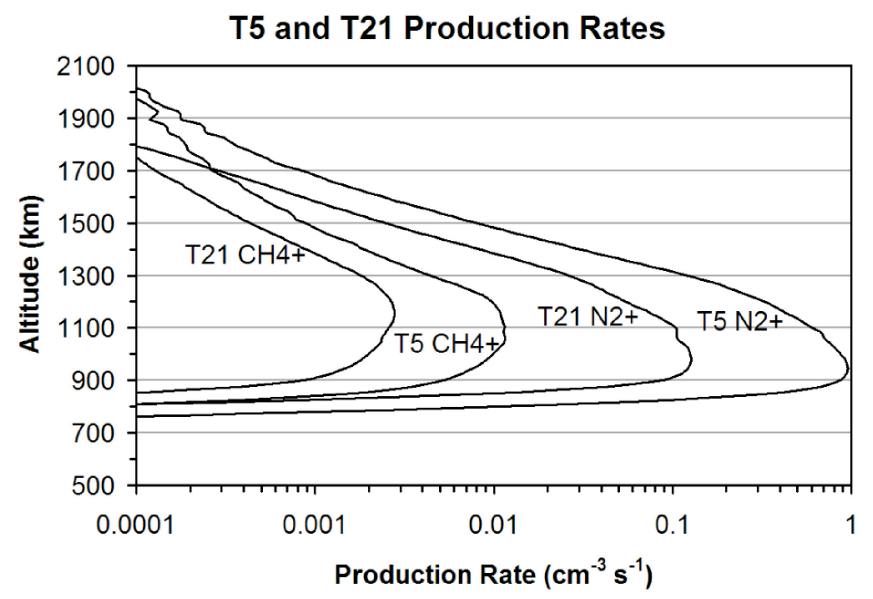

Figure 5. Production rates versus altitude for $\mathrm{N}_{2}^{+}$and $\mathrm{CH}_{4}^{+}$are shown for two cases: T5 CAPS ELS boundary electron fluxes and T21 CAPS ELS boundary fluxes, but both sets of production rates were reduced by a factor of 2.5 before being plotted.

that significant ion production is present down to $800 \mathrm{~km}$, well below the spacecraft CA altitude, but note that our model does not include electrons with energies greater than $5 \mathrm{keV}$ and does not include energetic ion precipitation (Cravens et al. 2008), so that below about 800-900 km Figure 5 is missing some possible sources of ionization.

At lower altitudes $(\mathrm{z}<1100 \mathrm{~km})$ the calculated ion production rates depend on the field line topology adopted but the production rates at higher altitudes are not sensitive to this topology. Only the case of magnetic field lines anchored at the surface are shown in Figure 5. Also note that the T5 ion production rates shown here agree rather well with the production rates above $1000 \mathrm{~km}$ shown by Agren et al. (2007) if adjusted by the factor of 4 discussed earlier.

\section{Description of the ionospheric model}

Numerous models of Titan's ionosphere have been published over the last twenty years or so (see the introduction). The basic model used in this paper was described in a series of papers (Keller et al. 1992, 1994, 1998; Keller and Cravens 1994; Gan et al. 1992, 1993; Cravens et al. 2004, 2005). As mentioned earlier, we have now "upgraded" the chemistry in this model to include most of the chemistry (and minor neutral species) presented by Vuitton et al. (2006, 2007). Our ionospheric model has several flavors: photochemical (no time-dependence or 
transport), one-dimensional transport ("polar wind" type model for Titan's wake), and onedimensional, time-dependent MHD models. The transport versions of the models have only a few ion species and simple chemical schemes. For example, Cravens et al. (1998) published a 3species MHD model including simple chemistry. Similarly, Ma et al. (2004) developed a 7species three-dimensional, global MHD model with a simplified version of the Keller et al. (1998) chemical scheme. De La Haye et al. (2008a) also adopted the Keller et al. (1998) ion chemistry scheme but coupled this with a neutral chemistry scheme, and used a rotating method to account for diurnal variation of solar inputs, providing local-time dependent results at constant latitude.

Density profiles for the major neutral species as a function of altitude and position along a field line are needed for the two-stream model and for the ionospheric model. We adopted $\mathrm{N}_{2}$ and $\mathrm{CH}_{4}$ densities measured during the outbound T5 pass by the INMS in its closed source neutral (csn) mode (Waite et al. 2005). $\mathrm{N}_{2}$ and $\mathrm{CH}_{4}$ density profiles are extended to altitudes below the CA altitude with the Vervack et al. (2004) density profiles. Neutral density profiles for one of our several neutral model cases are shown in Figure 3. The minor neutral species used in our model (e.g., $\mathrm{HCN}, \mathrm{C}_{2} \mathrm{H}_{2}, \mathrm{C}_{2} \mathrm{H}_{4}, \mathrm{C}_{2} \mathrm{H}_{6}, \ldots$ ) come from several sources of information, but are mainly based on csn measurements by the INMS (e.g., Waite et al., 2005). The Vuitton et al. $(2006,2007)$ papers provided another information source for minor species not measured by INMS but deduced from measured ion densities (i.e., Cravens et al. 2006). Several neutral model cases were adopted and mixing ratios at $1100 \mathrm{~km}$ for some species are shown in Table 1 .

A large number of cases were originally tried but only a sampling is shown here (and hence the case designations B2, B4, ..). First consider the B2 and B4 cases. The relative altitude profiles from Toublanc et al. (1995) were adopted when possible but these were adjusted to the mixing ratios measured at $1100 \mathrm{~km}$ by the INMS or from values published by Vuitton et al. (2006, 2007). The HCN profile given by Toublanc et al. was adopted, but sometimes with some modification as noted in the table. For case $\mathrm{B} 5$, we also reduced the $\mathrm{HCNH}^{+}$recombination rate coefficient (not a change in the neutral model but we treat this as a separate case anyway).

A number of minor nitrile (and other nitrogen-bearing) neutral species were deduced by Vuitton et al. which we adopted for the C2 case. Vuitton et al. only reported on results at 1100 $\mathrm{km}$, so for the "new" species we determined altitude profiles by adjusting the relevant minor neutral scale height to improve the ionospheric model agreement with measured INMS ion density profiles (e.g., see the ammonia/ $\mathrm{NH}_{4}+$ discussion later in the paper). This is the $\mathrm{C} 2$ case. Note that for the "B" cases we also adopted the minor nitrile or nitrogen-bearing neutral species from Vuitton et al., but not for the other species (i.e., $\mathrm{C}_{2} \mathrm{H}_{2}, \mathrm{C}_{2} \mathrm{H}_{4}, \mathrm{HCN}$...). For one case (D2), we also multiplied all neutral densities (including $\mathrm{N}_{2}$ and $\mathrm{CH}_{4}$ ) at all altitudes by a factor of 2.5.

For the current paper we used both a photochemical ionospheric code and a time-dependent code with 71 ion species and several hundred chemical reactions. The electron density was assumed to be the sum of the densities of all ion species (i.e., quasi-neutrality is assumed). The electron temperature profile (needed for dissociative recombination rate coefficients) was taken from T5 RPWS/LP measurements (see Agren et al. 2007). Note that the temperature is Te $\approx 500$ $\mathrm{K}-1000 \mathrm{~K}$ for most of the ionosphere. The hundreds of reaction rate coefficients needed for the chemistry are described in papers listed in the introduction and earlier in this section, and particularly by Keller et al. (1992, 1998), Vuitton et al. (2006, 2007), and Anicich et al. (1997, 2004). Also see the discussion by Carrasco et al. (2007) on the sensitivity of Titan chemical models to uncertainties in rate coefficients. 
Primary ion production is ultimately balanced by dissociative recombination. McClain et al. (2004), and references therein, discuss many of the important dissociative recombination rate coefficients. Coates et al. (2007a) described the discovery of negative ions in the lower ionosphere of Titan by Cassini. Evidently, negative ion densities can become significant below about $1000 \mathrm{~km}$, but our model, focusing on higher altitudes (and also because at this moment a good understanding of the sources or sinks of negative ions at Titan does not exist), does not include negative ions.

The continuity equation for ion species $\mathrm{s}$ is given by:

$$
\frac{\partial n_{s}}{\partial t}+\nabla \cdot\left(n_{s} \mathbf{u}_{s}\right)=P_{s}-L_{s}
$$

where $\mathrm{n}_{\mathrm{s}}$ is the density of ion species $\mathrm{s}$, and $\mathbf{u}_{\mathrm{s}}$ is the bulk flow velocity of ion species $\mathrm{s}$. $\mathrm{P}_{\mathrm{s}}$ and $\mathrm{L}_{\mathrm{s}}$ are the chemical production and loss rates of species $\mathrm{s}$, respectively. $\mathrm{P}_{\mathrm{s}}$ includes primary production as well as production from ion-neutral chemistry. $\mathrm{L}_{\mathrm{s}}$ includes losses due to ionneutral chemistry and dissociative recombination. For the models presented in this paper, we neglect the transport terms (i.e., let $\mathbf{u}_{\mathrm{s}}=0$ ). The Ma et al. (2006) global MHD calculations demonstrated that this photochemical assumption is reasonable for altitudes less than about 1450 $\mathrm{km}$. For the photochemical model we solve the set of 71 equations found by setting $\mathrm{dn}_{\mathrm{s}} / \mathrm{dt}=0$ (that is, $\mathrm{P}_{\mathrm{s}}=\mathrm{L}_{\mathrm{s}}$ ), and for our time-dependent model we adopt time-varying primary production rates and solve the coupled 71 first order differential equations as functions of time using a 4th order Runge-Kutta method.

Space limitations prevent an extensive discussion of the complex chemistry operating in Titan's ionosphere (see Keller et al. 1992, 1998; Vuitton et al. 2006, 2007: Fox and Yelle 1997; Wilson and Atreya 2004; De La Haye et al. 2008a; Waite et al. 2007), but a very brief summary is given in this section. The main ion species produced by electron impact ionization $\left(\mathrm{N}_{2}^{+}, \mathrm{N}^{+}\right.$, $\mathrm{CH}_{4}{ }^{+}, \mathrm{CH}_{3}{ }^{+}, \ldots$ ) were discussed earlier. Ion-neutral chemistry associated with both major neutral species and minor species (i.e., acetylene, ethylene, ethane, hydrogen cyanide, benzene,....) then acts to transform these "primary" ion species into a large number of complex hydrocarbon and nitrogen-bearing ion species. For example, two of the most abundant ion species predicted by pre-Cassini models $\left(\mathrm{C}_{2} \mathrm{H}_{5}{ }^{+}\right.$and $\left.\mathrm{HCNH}^{+}\right)$are created via the following sequence of chemical reactions (Anicich et al., 2004):

$$
\begin{gathered}
\mathrm{N}_{2}^{+}+\mathrm{CH}_{4} \rightarrow \mathrm{CH}_{3}^{+}+\mathrm{N}_{2}+\mathrm{H} \\
\mathrm{CH}_{3}^{+}+\mathrm{CH}_{4} \rightarrow \mathrm{C}_{2} \mathrm{H}_{5}^{+}+\mathrm{H}_{2} \\
\mathrm{C}_{2} \mathrm{H}_{5}^{+}+\mathrm{HCN} \rightarrow \mathrm{HCNH}^{+}+\mathrm{C}_{2} \mathrm{H}_{4}
\end{gathered}
$$


Table 1. Neutral Composition of Titan's Thermosphere Used in the Model

\begin{tabular}{|c|c|c|c|c|c|c|}
\hline \multicolumn{7}{|c|}{ TABLE 1} \\
\hline \multicolumn{7}{|c|}{ MODEL CASE MIXING RATIOS } \\
\hline NEUTRAL & B2 & B4 & B5 & $\mathrm{C} 2$ & D2 & G5 \\
\hline $\mathrm{N}_{2}$ & 0.965 & 0.960 & 0.965 & 0.965 & 0.966 & 0.962 \\
\hline $\mathrm{CH}_{4}$ & 0.025 & 0.029 & 0.025 & 0.025 & 0.025 & 0.025 \\
\hline $\mathrm{H}_{2}$ & $4681 *$ & 4660* & $4681 *$ & 4688* & 4697* & 4317* \\
\hline $\mathrm{N}$ & 1069* & 1064* & 1069* & $61.73 *$ & $61.66 *$ & 1066* \\
\hline $\mathrm{C}_{2} \mathrm{H}_{2}$ & 182* & $181 *$ & 182* & $278^{*}$ & $279 *$ & $141 *$ \\
\hline $\mathrm{C}_{2} \mathrm{H}_{4}$ & 696* & 693* & 696* & 988* & 988* & 4626* \\
\hline $\mathrm{HCN}$ & 1352* & 1344* & 1351 & $398^{*}$ & $399 *$ & $342 *$ \\
\hline $\mathrm{C} 2 \mathrm{H} 6$ & $4.66 *$ & $4.64 *$ & $4.66 *$ & $120^{*}$ & $120^{*}$ & 156* \\
\hline $\mathrm{H}$ & 1003* & 998* & 1003* & 991* & 991* & $1000 *$ \\
\hline $\mathrm{C}_{3} \mathrm{HN}$ & $0.458 *$ & $0.456 *$ & $0.458^{*}$ & $42.85 *$ & 42.92* & $7.284 *$ \\
\hline $\mathrm{C}_{3} \mathrm{H}_{4}$ & $2.12 *$ & $2.48^{*}$ & $2.12 *$ & $4.06^{*}$ & $4.05 *$ & $13.0 *$ \\
\hline $\mathrm{H}_{2} \mathrm{O}$ & $2.59 *$ & $2.58 *$ & $2.59 *$ & $0.29 *$ & $0.29 *$ & 25.83* \\
\hline $\mathrm{C}_{3} \mathrm{H}_{8}$ & 1.06* & $1.05^{*}$ & 1.06* & $2.41 *$ & $2.41 *$ & $4.22 *$ \\
\hline $\mathrm{C}_{4} \mathrm{H}_{2}$ & $0.586 *$ & $0.583 *$ & $0.586 *$ & $10.42 *$ & 10.42* & 44.34* \\
\hline $\mathrm{NH}_{3}$ & $4.27 *$ & $4.25^{*}$ & $4.27 *$ & $6.47 *$ & $6.46 *$ & $4.25^{*}$ \\
\hline $\mathrm{CH}_{2} \mathrm{NH}$ & $8.53 *$ & $2.83 *$ & $2.84 *$ & $9.65^{*}$ & $9.65 *$ & $8.51^{*}$ \\
\hline $\mathrm{C}_{2} \mathrm{H}_{3} \mathrm{CN}$ & $0.066 *$ & $1.31 *$ & $1.32 *$ & $9.65^{*}$ & 9.65* & $242 *$ \\
\hline $\mathrm{C}_{2} \mathrm{H}_{5} \mathrm{CN}$ & $0.095^{*}$ & $0.094 *$ & $0.095^{*}$ & $0.488^{*}$ & $0.487^{*}$ & $0.465 *$ \\
\hline $\mathrm{CH}_{3} \mathrm{NH}_{2}$ & 0.0899* & 0.0895* & 0.0899* & 0.0097* & 0.0096* & $0.269 *$ \\
\hline $\mathrm{C}_{6} \mathrm{H}_{6}$ & $0.074 *$ & $0.074 *$ & $0.074^{*}$ & $3.33 *$ & $3.33 *$ & - \\
\hline $\mathrm{C}_{6} \mathrm{H}_{2}$ & $0.834 *$ & $0.831 *$ & $0.834^{*}$ & $0.827^{*}$ & $0.827^{*}$ & - \\
\hline $\mathrm{C}_{7} \mathrm{H}_{4}$ & $0.313^{*}$ & $0.311^{*}$ & $0.313^{*}$ & $0.310 *$ & $0.310 *$ & - \\
\hline $\mathrm{C}_{7} \mathrm{H}_{8}$ & $0.209 *$ & $0.208 *$ & $0.209 *$ & $0.207^{*}$ & $0.207^{*}$ & - \\
\hline $\mathrm{C}_{8} \mathrm{H}_{2}$ & $0.209 *$ & $0.208^{*}$ & $0.209 *$ & $0.207^{*}$ & $0.207^{*}$ & - \\
\hline $\mathrm{C}_{4} \mathrm{H}_{3} \mathrm{~N}$ & $4.17 *$ & $4.15^{*}$ & $4.17 *$ & 4.136* & $4.134 *$ & - \\
\hline $\mathrm{HC}_{5} \mathrm{~N}$ & 1.043* & $1.038^{*}$ & 1.043* & 1.034* & 1.033* & - \\
\hline $\mathrm{C}_{5} \mathrm{H}_{5} \mathrm{~N}$ & $0.417^{*}$ & $0.415^{*}$ & $0.417^{*}$ & $0.414 *$ & 0.413* & - \\
\hline $\mathrm{C}_{6} \mathrm{H}_{3} \mathrm{~N}$ & $0.313^{*}$ & $0.311^{*}$ & $0.313 *$ & $0.310 *$ & $0.310 *$ & - \\
\hline $\mathrm{C}_{6} \mathrm{H}_{7} \mathrm{~N}$ & $0.104 *$ & $0.104 *$ & $0.104^{*}$ & $0.104^{*}$ & $0.103 *$ & - \\
\hline
\end{tabular}

* Parts per million by volume

B2: INMS major and minor neutrals. Scale heights, at altitudes other than $1100 \mathrm{~km}$, adjusted to achieve better results. $\mathrm{HCN}=$ Toublanc $* 2$.

B4: $\quad \mathrm{CH} 2 \mathrm{NH}$ reduced by factor of 3 from $\mathrm{B} 2$ $\mathrm{C} 2 \mathrm{H} 3 \mathrm{CN}$ reduced by factor of 20 from $\mathrm{B} 2$ $\mathrm{HCN}=$ Toublanc $* 2$ 
B5: Recombination rate of $\mathrm{HCNH}+$ doubled.

C2: $\quad$ B2/B4 altitude dependence of densities but Vuitton et al [2006, 2007] mixing ratios adjusted to $1100 \mathrm{~km}$. HCN mixing ratio is doubled from Vuitton et al.

D2: $\quad$ Multiplied all C2 neutrals by a factor of 2.5

G5: INMS majors and most INMS minor neutrals.

Another important reaction converts $\mathrm{CH}_{4}^{+}$to $\mathrm{CH}_{5}^{+}$:

$$
\mathrm{CH}_{4}^{+}+\mathrm{CH}_{4} \rightarrow \mathrm{CH}_{5}^{+}+\mathrm{CH}_{3}
$$

Reactions with the major neutral species $\left(\mathrm{N}_{2}\right.$ or $\left.\mathrm{CH}_{4}\right)$ are rapid so that rate of reaction A1 almost equals the primary production rate of $\mathrm{N}_{2}{ }^{+}$and the rate of reaction $\mathrm{A} 4$ almost equals the primary production rate of $\mathrm{CH}_{4}{ }^{+}$. Hence, $\mathrm{CH}_{3}{ }^{+}, \mathrm{CH}_{4}{ }^{+}$, and $\mathrm{CH}_{5}{ }^{+}$ions can be considered to be primary (or almost primary) ion species. $\mathrm{CH}_{5}{ }^{+}$is converted to $\mathrm{C}_{2} \mathrm{H}_{5}{ }^{+}$via reactions with acetylene and ethylene. $\quad \mathrm{N}_{2}{ }^{+}$density measurements by INMS cannot be used to assess the primary ion production rate because a much more abundant mass 28 species is $\mathrm{HCNH}^{+}$(the most abundant species observed during T5). Reaction of (5) of $\mathrm{C}_{2} \mathrm{H}_{5}{ }^{+}$with hydrogen cyanide is the main source of $\mathrm{HCNH}^{+}$(protonated hydrogen cyanide) and the ratio of $\mathrm{HCNH}^{+}$to $\mathrm{C}_{2} \mathrm{H}_{5}{ }^{+}$in the model output is very sensitive to the $\mathrm{HCN}$ density. Unfortunately, $\mathrm{HCN}$ cannot be accurately measured by INMS in its closed source neutral mode.

$\mathrm{HCNH}^{+}$is chemically removed by dissociative recombination with electrons as well as by reaction with a number of rather low abundance minor neutral species, thus producing higher mass hydrocarbon and nitrogen-bearing ion species (see Fox and Yelle 1997; Keller et al. 1998; Vuitton et al. 2006, 2007). Higher-mass ion species can also be produced by reaction of $\mathrm{C}_{2} \mathrm{H}_{5}{ }^{+}$ with neutral hydrocarbon and nitrile or other nitrogen-bearing molecules.

Some nitrogen-bearing ion species are not very reactive and are mainly lost via dissociative recombination (i.e., these are "terminal" ions), giving them rather long lifetimes. Two important examples of relatively low mass terminal (or almost terminal) ions were discussed in the introduction -- mass 18 and 30 ion species were not expected in pre-Cassini models to be very abundant (thought to be $\mathrm{H}_{3} \mathrm{O}^{+}$and $\mathrm{C}_{2} \mathrm{H}_{6}^{+}$mainly), but it is now thought that $\mathrm{NH}_{4}^{+}$(Cravens et al . 2006; Vuitton et al. 2006; Wilson and Atreya 2004) and $\mathrm{CH}_{2} \mathrm{NH}_{2}{ }^{+}$(Vuitton et al. 2006) are much more likely candidates. Two of the source reactions for these "new" ion species are:

$$
\begin{gathered}
\mathrm{HCNH}^{+}+\mathrm{NH}_{3} \rightarrow \mathrm{NH}_{4}^{+}+\mathrm{HCN} \\
\mathrm{HCNH}^{+}+\mathrm{CH}_{2} \mathrm{NH}-\rightarrow \mathrm{CH}_{2} \mathrm{NH}_{2}^{+}+\mathrm{HCN}
\end{gathered}
$$

We used our photochemical model to calculate chemical lifetimes of several ion species in different parts of the chemical scheme, and some of these are plotted in Figure 6. The chemical lifetime for a given species is the inverse of the sum over all loss reactions of the rate coefficient multiplied by the relevant reactant abundance (i.e., density of the relevant neutral or for dissociative recombination, the electron density). Except for terminal, or almost terminal, ion species (such as $\mathrm{CH}_{2} \mathrm{NH}_{2}{ }^{+}$or $\mathrm{NH}_{4}{ }^{+}$) these lifetimes mainly depend on the densities of the relevant neutral species acting in the loss reactions (i.e., $\mathrm{N}_{2}, \mathrm{CH}_{4}, \mathrm{C}_{2} \mathrm{H}_{2}, \mathrm{HCN}$, etc.). A few ion species listed in order of increasing chemical lifetime are: $\mathrm{CH}_{4}^{+}$(reaction with the major species $\mathrm{CH}_{4}$ ), 
$\mathrm{CH}_{5}^{+}$(reaction with $\mathrm{C}_{2} \mathrm{H}_{2}$ and $\mathrm{C}_{2} \mathrm{H}_{4}$ ), $\mathrm{C}_{2} \mathrm{H}_{5}^{+}$(reaction with $\mathrm{HCN}$ ), $\mathrm{HCNH}^{+}$(reaction with ammonia, some nitriles, and electrons), and $\mathrm{CH}_{2} \mathrm{NH}_{2}{ }^{+}$(representative of terminal ions - reaction with electrons). The transport times shown in Figure 6 will be discussed again later. In general,

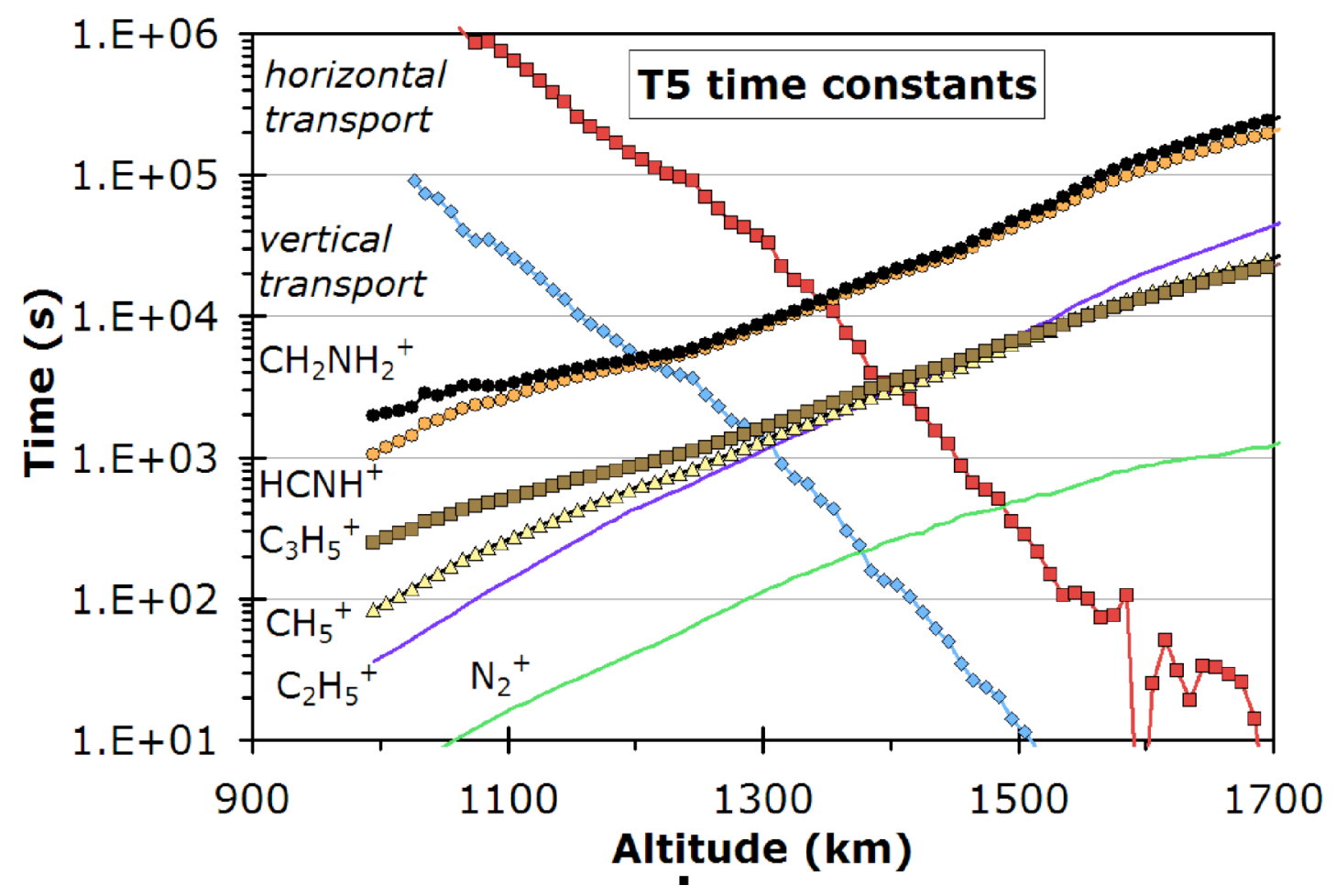

Figure 6. Chemical lifetimes versus altitude for several ion species and for the B4 neutral model case for T5. Also shown are estimated vertical and horizontal transport times versus altitude. T21 chemical time constants (not shown) for the short-lived species are similar but for terminal species are about 3 times larger (due to the lower electron density).

except for terminal ions, the chemical lifetimes increase with altitude because the neutral reactant densities decrease with altitude. The terminal ion lifetimes (and also to a lesser extent $\mathrm{HCNH}^{+}$ lifetimes) are about a factor of 3 longer for T21 (not shown) than for T5 due to lower electron densities.

Note that the "actual" time history of the density of a species, which we determined using our time-dependent model, usually reflects the chemical lifetime, but not always. What also matters is how far down the chemical chain the species resides (see the chemical flow chart in Keller et al. 1998).

\section{Comparison of ionospheric model results with Cassini data}

High mass-resolution mass spectra for ion species were measured by the INMS on the outbound leg of the T5 encounter (Cravens et al. 2006). For this INMS open source ion (osi) instrument mode, ions entering the instrument aperture are deflected by a quadrapole switching 
lens (set to the necessary voltages) and are then guided to the radio-frequency mass analyzer, which selects ions according to their mass-to-charge ratio (m/z) (Waite et al. 2004, 2005; Kasprzak et al. 1996). The ions are then detected with a secondary electron multiplier. The field of view has a half-width of $\approx 3^{\circ}$, and the instrument measures positive ions with kinetic energies appropriate for a "compensation" speed equal to the spacecraft speed $(6.02 \mathrm{~km} / \mathrm{s}$ in this case). Ion densities were also measured by the INMS during the T21 encounter, but (unlike T5) a high spacecraft potential existed and a large and uncertain correction factor was applied to this data set. The effects of spacecraft potential will be described in a future paper (Kasprzak et al., in preparation). Note that the INMS ion densities presented in the current paper for T5 (and now corrected for spacecraft potential) are less than about $20 \%$ different, depending on the mass number, from densities shown by Cravens et al. (2006). The current paper will show INMS data points from each $34 \mathrm{~ms}$ integration period available for the relevant mass number. The ion density that corresponds to 1 count is close to $.006 \mathrm{~cm}^{-3}$.

The results of our photochemical model are now compared with INMS and RPWS/LP data. Several different assumptions concerning the magnetic field topology and the neutral composition were made, as discussed earlier. Table 1 lists relative neutral abundances for several model cases and for an altitude of $1100 \mathrm{~km}$. Note that calculated electron density

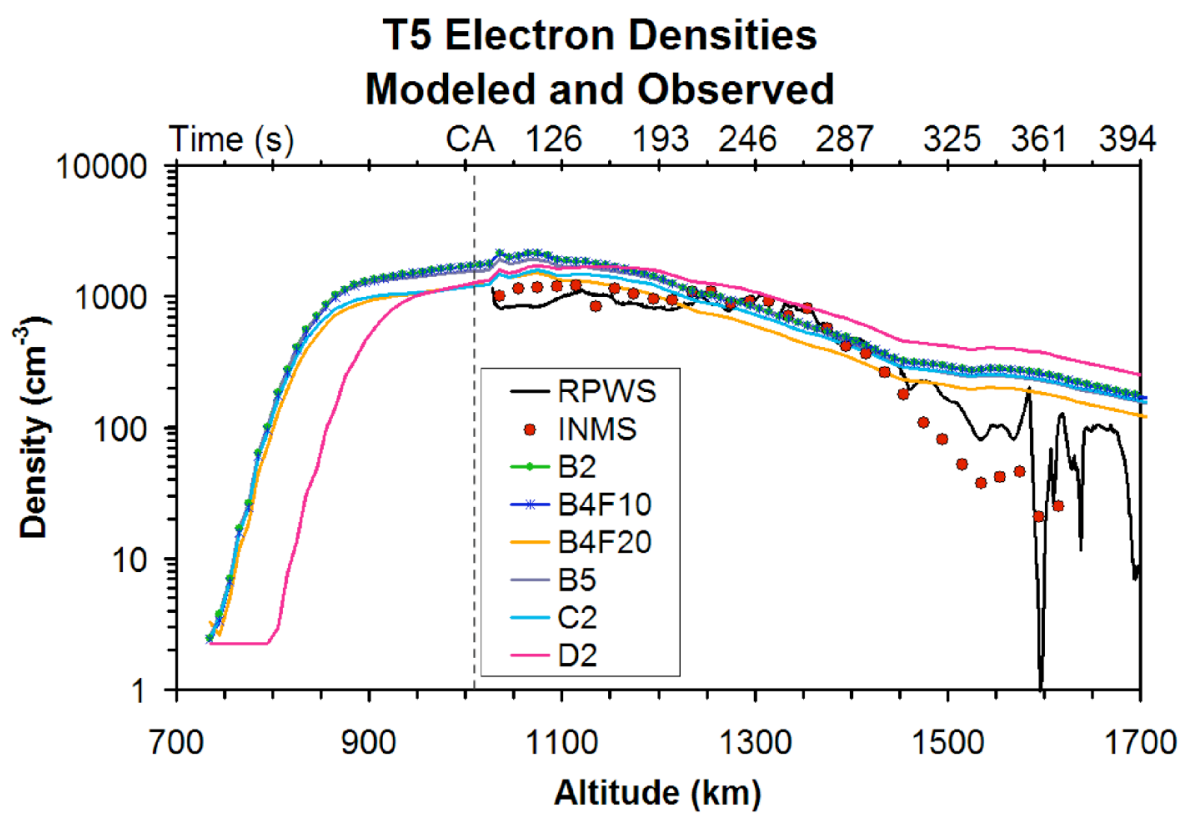

Figure 7. Calculated electron density versus altitude profiles are shown for the case of the parabolic magnetic field anchored at the surface of Titan and for several different model atmospheres as described in the text. A scale is also shown at the top for spacecraft time from closest approach (CA). Also shown is the electron density profile for the outbound leg of the Cassini T5 pass measured by the Langmuir probe on the RPWS/LP experiment (see Agren et al. 2007 and Cravens et al. 2006). Also shown is the total ion density profile from the INMS experiment. The vertical dashed line indicates the closest approach (CA) altitude of Cassini $(1027 \mathrm{~km})$. 
profiles do not depend much on details of the ion-neutral chemistry or on the abundances of minor neutrals, but they do depend on dissociative recombination rate coefficients and on the primary ion production rates. Figure 7 shows electron density profiles for several model runs all with the parabolic magnetic field lines anchored at the surface and all with a factor of 2.5 reduction of the incident magnetospheric electron fluxes (from CAPS ELS). The measured and model electron density profiles agree reasonably well (within a factor of $\approx 3$ ) particularly near $1400 \mathrm{~km}$. The densities appear to be somewhat too large near $1100 \mathrm{~km}$, suggesting that at lower altitudes a production rate correction factor more than a factor of 2.5 would be helpful.

Figure 8 shows electron density profiles for just one neutral model case but for three different field line configurations. All these profiles were obtained using the factor of 2.5 incident electron flux reduction factor. The calculated densities would have been about $60 \%$ higher than measured densities at $1400 \mathrm{~km}$ without this factor. Note that even better model-data agreement would have been obtained at lower altitudes if a factor of $5-10$ reduction in the incident electron flux had been used at lower altitudes (i.e. for higher energy incident electrons). Interestingly, the factor of 10 is the same depletion factor that looks best for the secondary electron fluxes (Figure 4). The most dramatic differences between the 3 model density profiles are evident below 1000 $\mathrm{km}$, where in situ spacecraft data is not available.

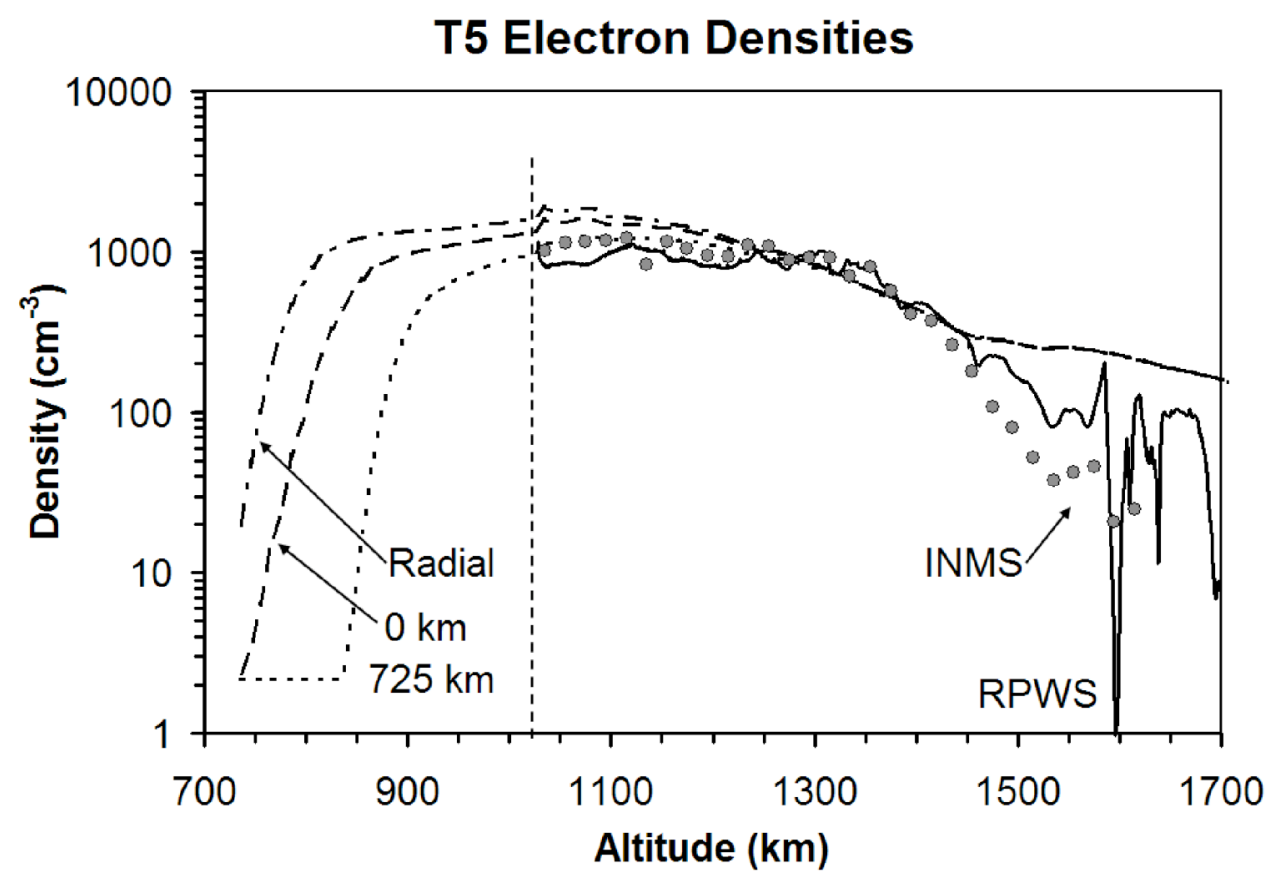

Figure 8. The same as Figure 7 but the calculated electron density profiles are all from the same neutral model atmosphere case (G1). However, 3 different magnetic field line configurations were used - radial field, parabolic anchored at the surface, and parabolic anchored at an altitude of $725 \mathrm{~km}$.

Now we describe model-data comparisons for the ion composition. Figure 9 shows comparisons for $\mathrm{CH}_{3}{ }^{+}$. This is an almost "primary" ion species created by reaction of $\mathrm{N}_{2}{ }^{+}$with 
methane (reaction A1) and its production rate is essentially that of $\mathrm{N}_{2}{ }^{+}$. The evident rather good agreement (except for small-scale variations) for this species indicates that the model has a reasonable $\mathrm{CH}_{4}$ density as well as a reasonable primary production rate of $\mathrm{N}_{2}{ }^{+}$. Details of the minor neutral composition are not important. The reasonable agreement between model and data also confirms that our primary ion production rate does need a reduction factor of at least 2.5. The B4F10 case (our "standard" factor of 2.5 incident flux model) does better at higher altitudes, and the B4F20 case (factor of 5 flux reduction) does better near closest approach, again suggesting a larger flux reduction factor at lower altitudes. The model version (case C2) using all of the Vuitton et al. neutral mixing ratios also does very well. Similar conclusions are reached for $\mathrm{CH}_{4}{ }^{+}$comparisons (Figure 10). $\mathrm{CH}_{4}{ }^{+}$is produced by ionization of $\mathrm{CH}_{4}$ and is lost via reaction with $\mathrm{CH}_{4}$, and again the model-data agreement mainly reflects on the basic primary ionization process.

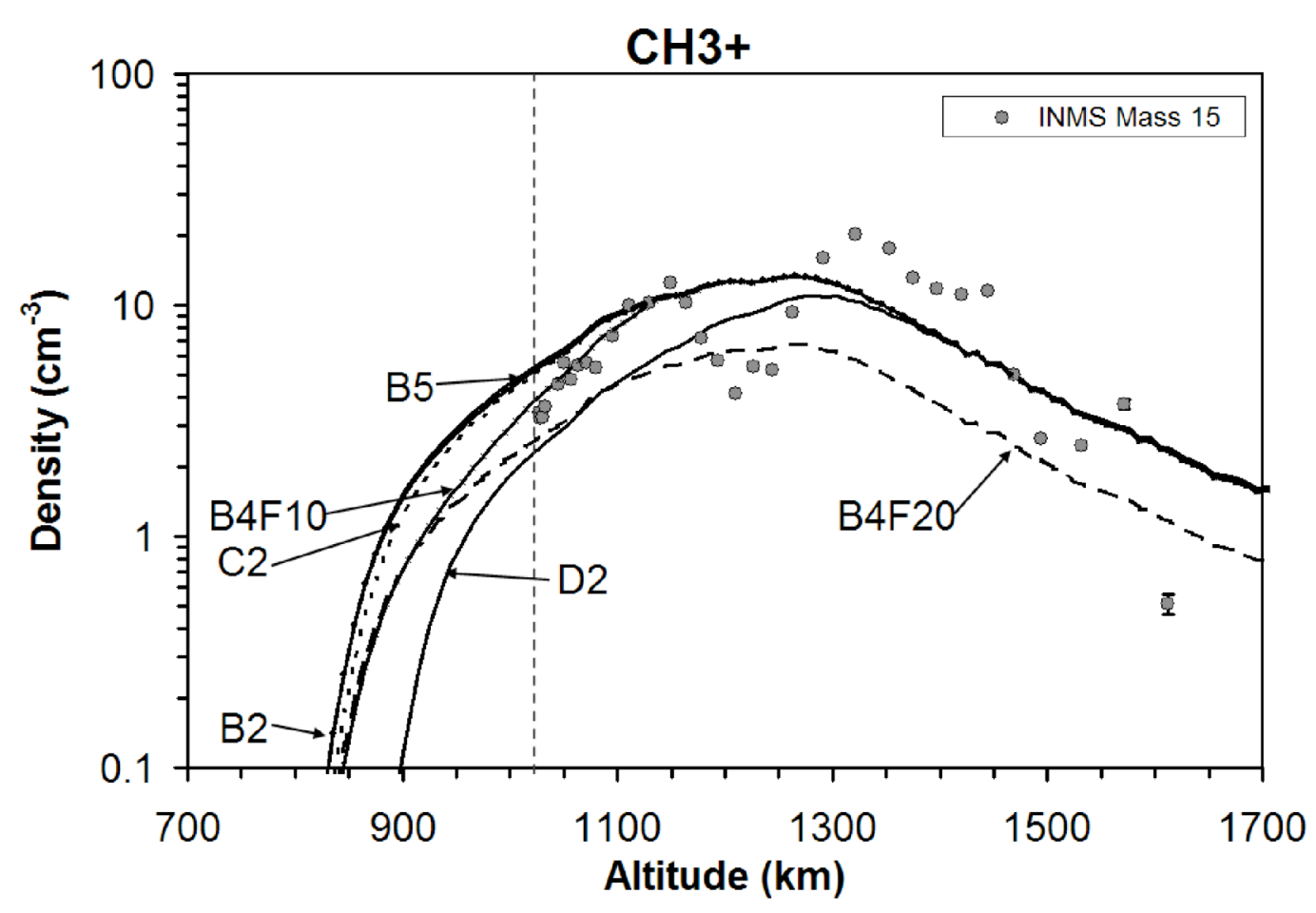

Figure 9. Calculated density versus altitude profile for $\mathrm{CH}_{3}{ }^{+}$for several model cases (different labeled lines). Also shown are the $\mathrm{m}=15$ densities measured by the INMS on T5. One sigma statistical error bars were shown for a couple of the INMS data points, but do not encompass all possible sources of error.

Figure 11 shows data-model comparisons for $\mathrm{CH}_{5}{ }^{+}$. In this case, the calculated densities are sensitive to the abundances of some "minor" neutral species $\left(\mathrm{C}_{2} \mathrm{H}_{2}, \mathrm{C}_{2} \mathrm{H}_{4}\right.$, and $\left.\mathrm{H}_{2}\right)$. Most of the model cases do reasonably well above about $1300 \mathrm{~km}$, but at lower altitudes the agreement is not good (model densities are $\approx 5$ times too high). The factor of 5 reduction model case (B4F20) does better than case B4F10 at lower altitudes. The best agreement is obtained with a model 
case (D2) for which $\mathrm{C}_{2} \mathrm{H}_{2}$ and $\mathrm{C}_{2} \mathrm{H}_{4}$ densities are larger. The Vuitton et al. $(2006,2007)$ model densities are also too high for $\mathrm{CH}_{5}^{+}$.

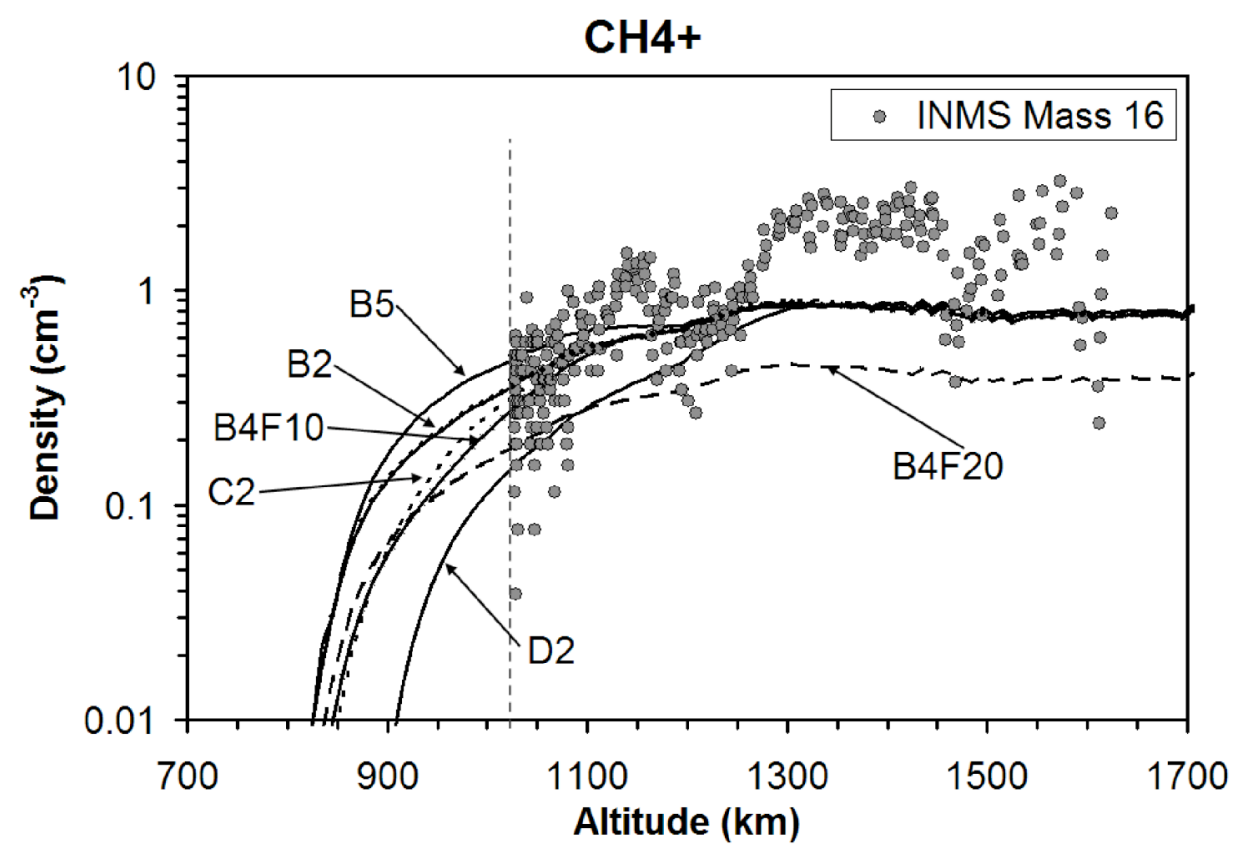

Figure 10. Calculated density versus altitude profile for $\mathrm{CH}_{4}{ }^{+}$for several model cases (different labeled lines). Also shown are the $\mathrm{m}=16$ densities measured by the INMS on T5.

We now discuss $\mathrm{C}_{2} \mathrm{H}_{5}^{+}$(Figure 12). This ion species is mainly produced from $\mathrm{CH}_{3}{ }^{+}$and its abundance is very sensitive to the $\mathrm{HCN}$ density. Considerable differences are present between different model cases for which the HCN density differs. Again, the B4F10 and C2 models are better than the B4F20 model at higher altitudes but not at lower altitudes. We found that it was difficult to obtain simultaneous good agreement for both $\mathrm{C}_{2} \mathrm{H}_{5}{ }^{+}$and for $\mathrm{HCNH}^{+}$at all altitudes by varying the $\mathrm{HCN}$ altitude profiles alone. Figure 3 shows our adopted $\mathrm{HCN}$ profile for case B4F10, and from Table 1 the relative $\mathrm{HCN}$ abundance at $1100 \mathrm{~km}$ is $1.34 \times 10^{-3}$.

Figure 13 shows data-model comparisons for $\mathrm{HCNH}^{+}$, an important ion species which is mainly produced by reaction of $\mathrm{C}_{2} \mathrm{H}_{5}^{+}$with $\mathrm{HCN}$ (reaction (4)). The density of this species is sensitive to the $\mathrm{HCN}$ abundance. All the model cases show reasonable agreement for altitudes above $1200 \mathrm{~km}$, and model C2 works best below this altitude, although none of the cases are great. The main problem is probably with the details of the HCN profile. The model case that works best for the combination of $\mathrm{HCNH}^{+}$and $\mathrm{C}_{2} \mathrm{H}_{5}{ }^{+}$comparisons is $\mathrm{C} 2$ but case D2 also works well. 


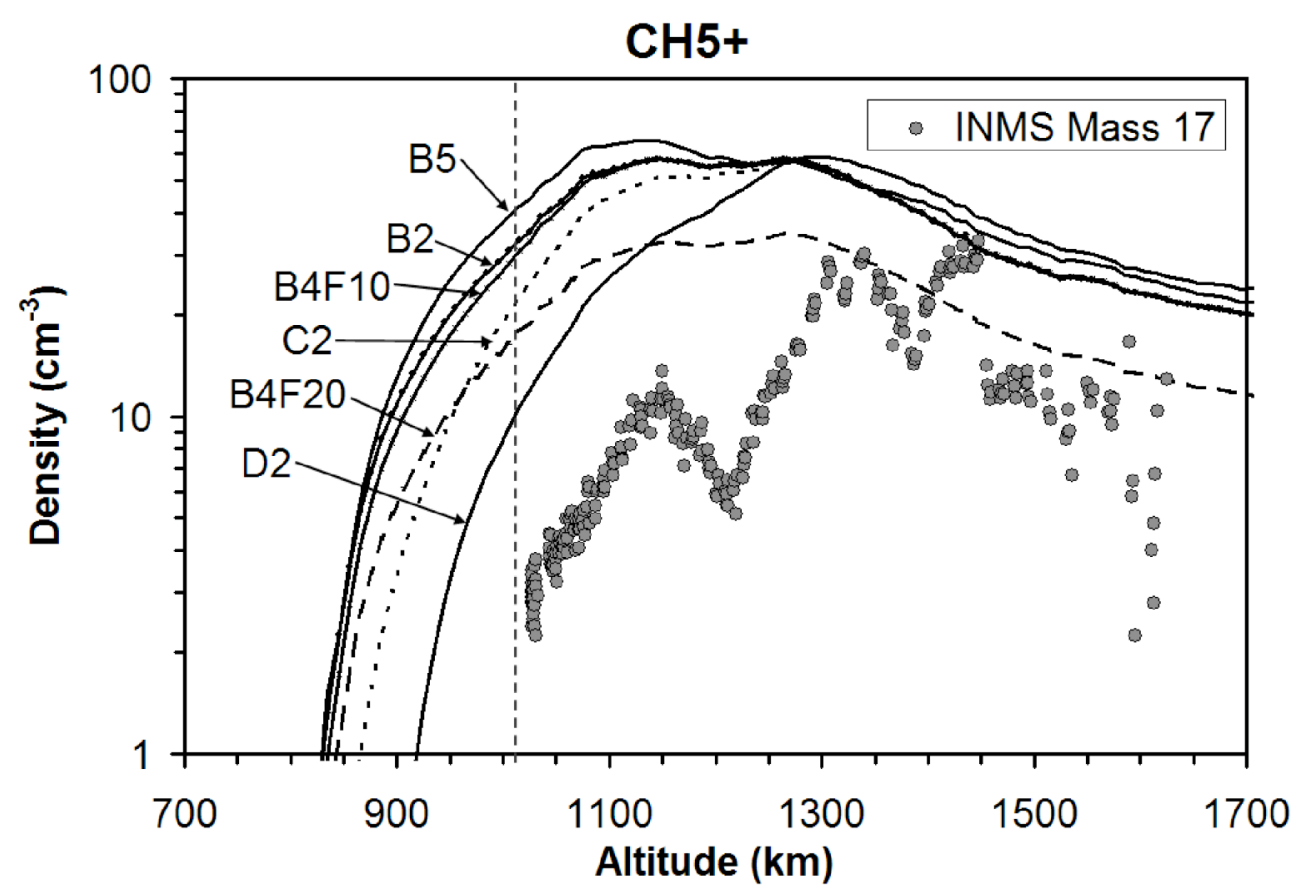

Figure 11. Calculated density versus altitude profile for $\mathrm{CH}_{5}{ }^{+}$for several model cases (different labeled lines). Also shown are the $\mathrm{m}=17$ densities measured by the INMS on T5.

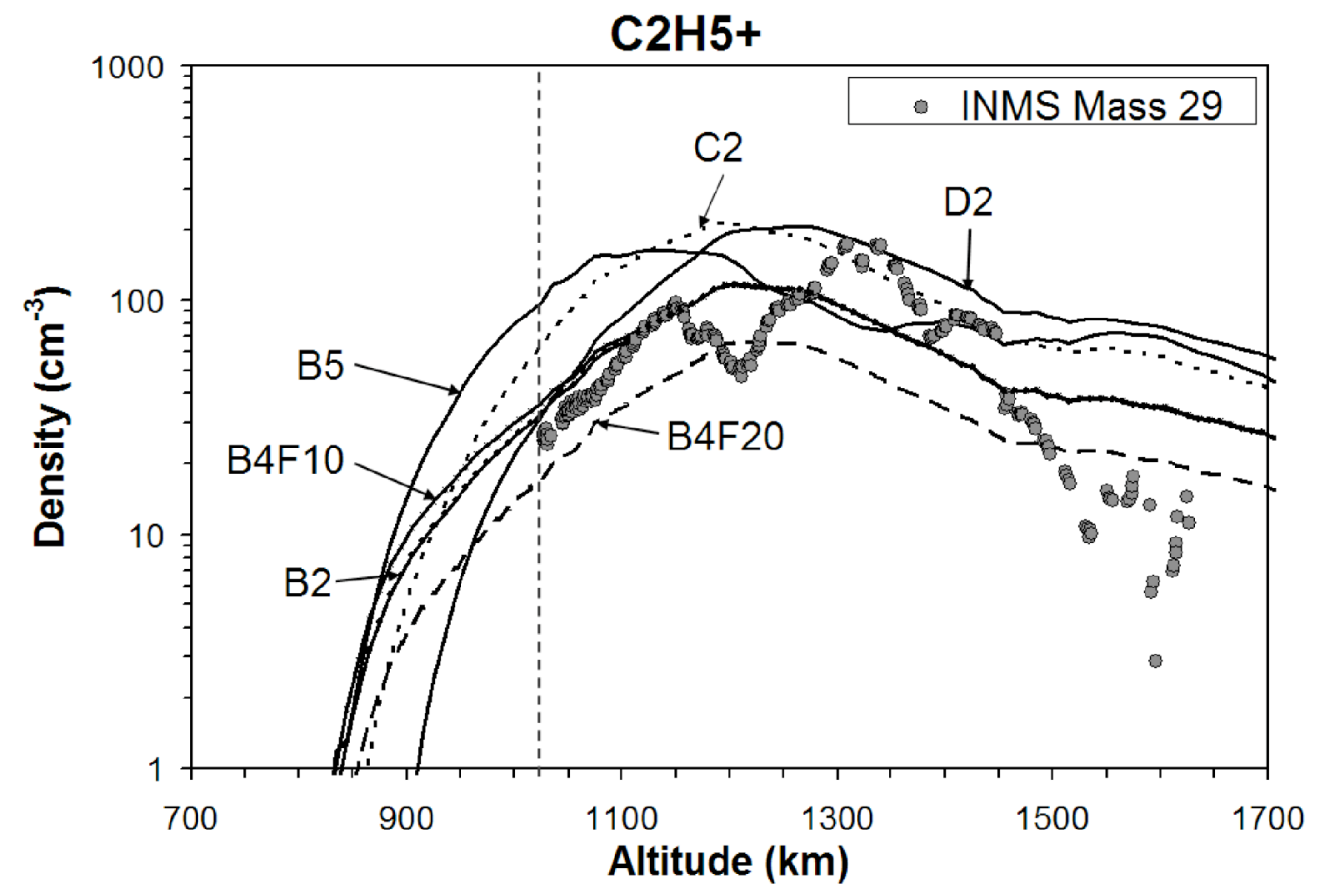

Figure 12. Calculated density versus altitude profile for $\mathrm{C}_{2} \mathrm{H}_{5}{ }^{+}$for several model cases (different labeled lines). Also shown are the $\mathrm{m}=29$ densities measured by the INMS on T5. 
Note that the modeled $\mathrm{HCNH}^{+}$density, as well as the electron density, falls off with altitude more slowly than the data does for altitudes above about $1450 \mathrm{~km}$. Transport processes are expected to become more important than chemistry at higher altitudes (see time constants in Figure 6) and photochemical models, such as ours, are no longer valid. Dynamical models are needed at higher altitudes, such as the multispecies MHD model of Ma et al. (2006).

An important higher-mass hydrocarbon species is $\mathrm{C}_{3} \mathrm{H}_{5}{ }^{+}$. This species is mainly produced by reaction of $\mathrm{C}_{2} \mathrm{H}_{5}^{+}$with $\mathrm{C}_{2} \mathrm{H}_{4}$ and it is lost via reaction with $\mathrm{C}_{2} \mathrm{H}_{4}$ and $\mathrm{C}_{2} \mathrm{H}_{2}$, producing even higher-mass hydrocarbon ion species such as $\mathrm{C}_{5} \mathrm{H}_{9}^{+}$. Comparisons are shown in Figure 14.

Figures 15 and 16 show density profiles of two terminal ion species, $\mathrm{CH}_{2} \mathrm{NH}_{2}{ }^{+}$and $\mathrm{NH}_{4}{ }^{+}$, respectively. The data-model agreement is excellent for these species for some cases because the neutral ammonia and $\mathrm{CH}_{2} \mathrm{NH}$ density profiles were designed to do just that (cf. Vuitton et al. 2006, 2007). A simple approximation (Cravens et al. 2006) to the $\mathrm{NH}_{4}{ }^{+}$density is given by $\left[\mathrm{NH}_{4}{ }^{+}\right] \approx \mathrm{k}\left[\mathrm{NH}_{3}\right] / \alpha \approx 10^{-3}\left[\mathrm{NH}_{3}\right]$, where $\mathrm{k}$ is the rate coefficient for the reaction of any major ion species with $\mathrm{NH}_{3}$ and $\alpha$ is the $\mathrm{NH}_{4}{ }^{+}$dissociative recombination rate coefficient. A relative abundance of $\mathrm{NH}_{3}$ of about 4 parts per million gives good data-model agreement.

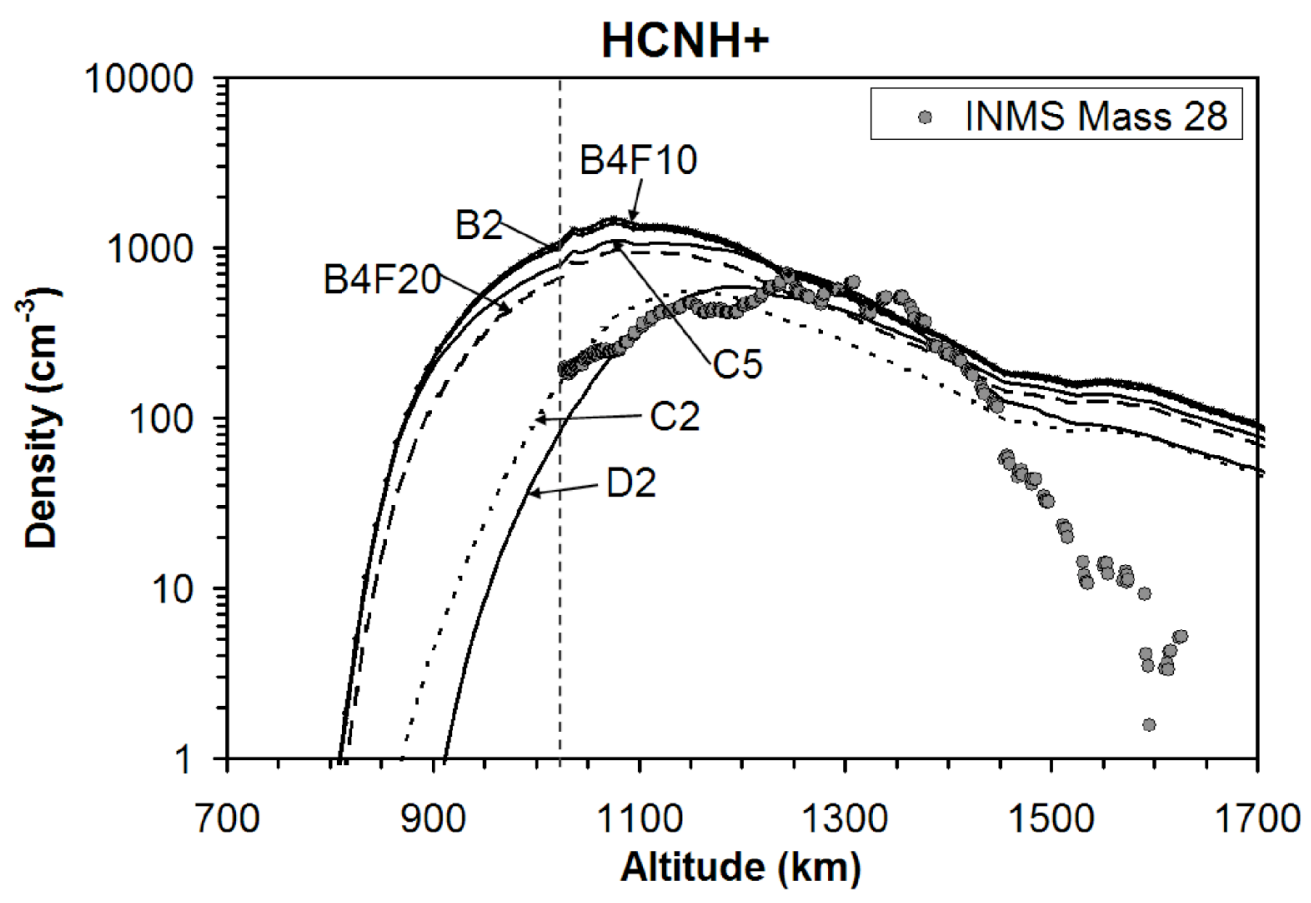

Figure 13. Calculated density versus altitude profile for $\mathrm{HCNH}^{+}$for several model cases (different labeled lines). Also shown are the $\mathrm{m}=28$ densities measured by the INMS on T5.

Detailed altitude profiles were shown only for a few ion species in this section. Figure 17 shows a complete comparison with INMS data of one of our calculated mass spectra (case B4) for an altitude of $1100 \mathrm{~km}$. The data-model agreement is reasonable within a factor of 2 for most species ( $\mathrm{m}=17, \mathrm{CH}_{5}{ }^{+}$has worse agreement). Although we are essentially using the Vuitton et al. chemistry, the primary ion production rates used in the current paper are somewhat different and 


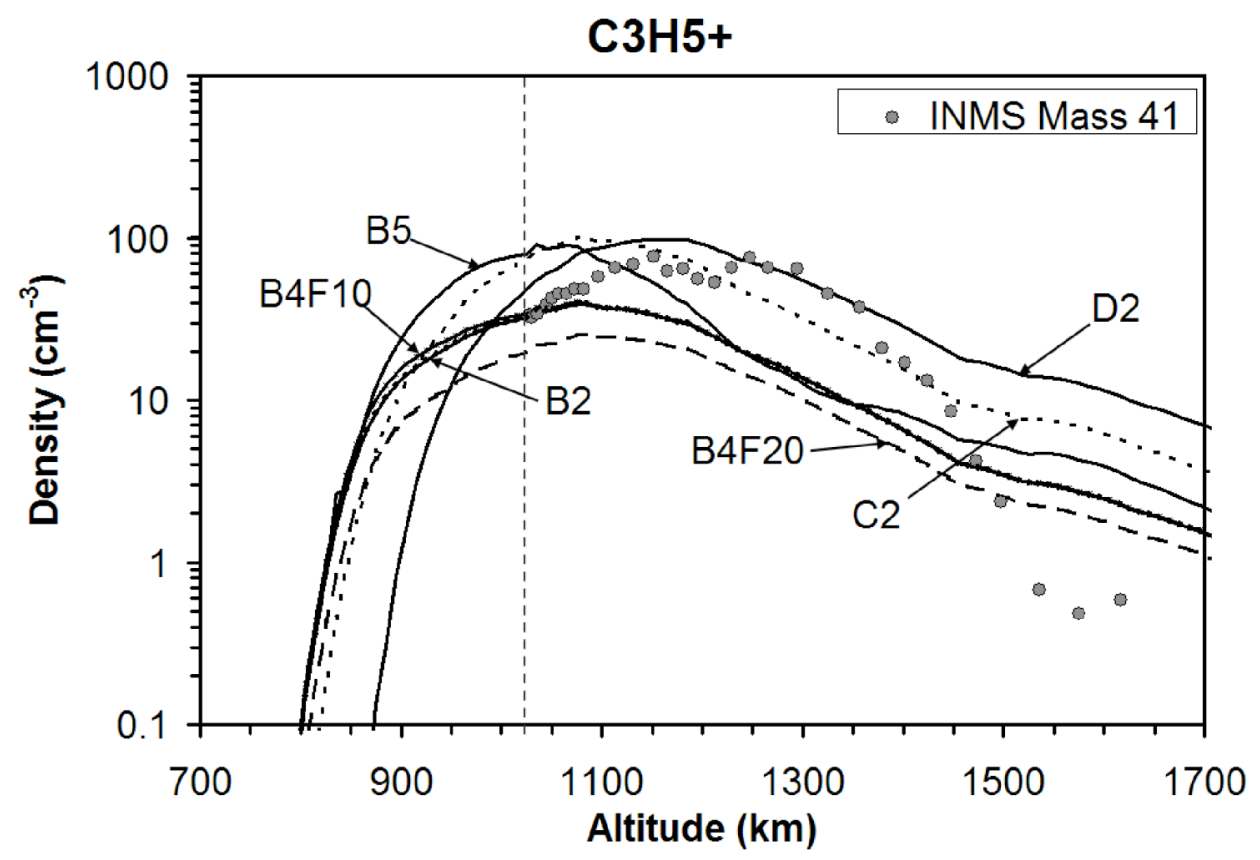

Figure 14. Calculated density versus altitude profile for $\mathrm{C}_{3} \mathrm{H}_{5}{ }^{+}$for several model cases (different labeled lines). Also shown are the $\mathrm{m}=41$ densities measured by the INMS on T5.

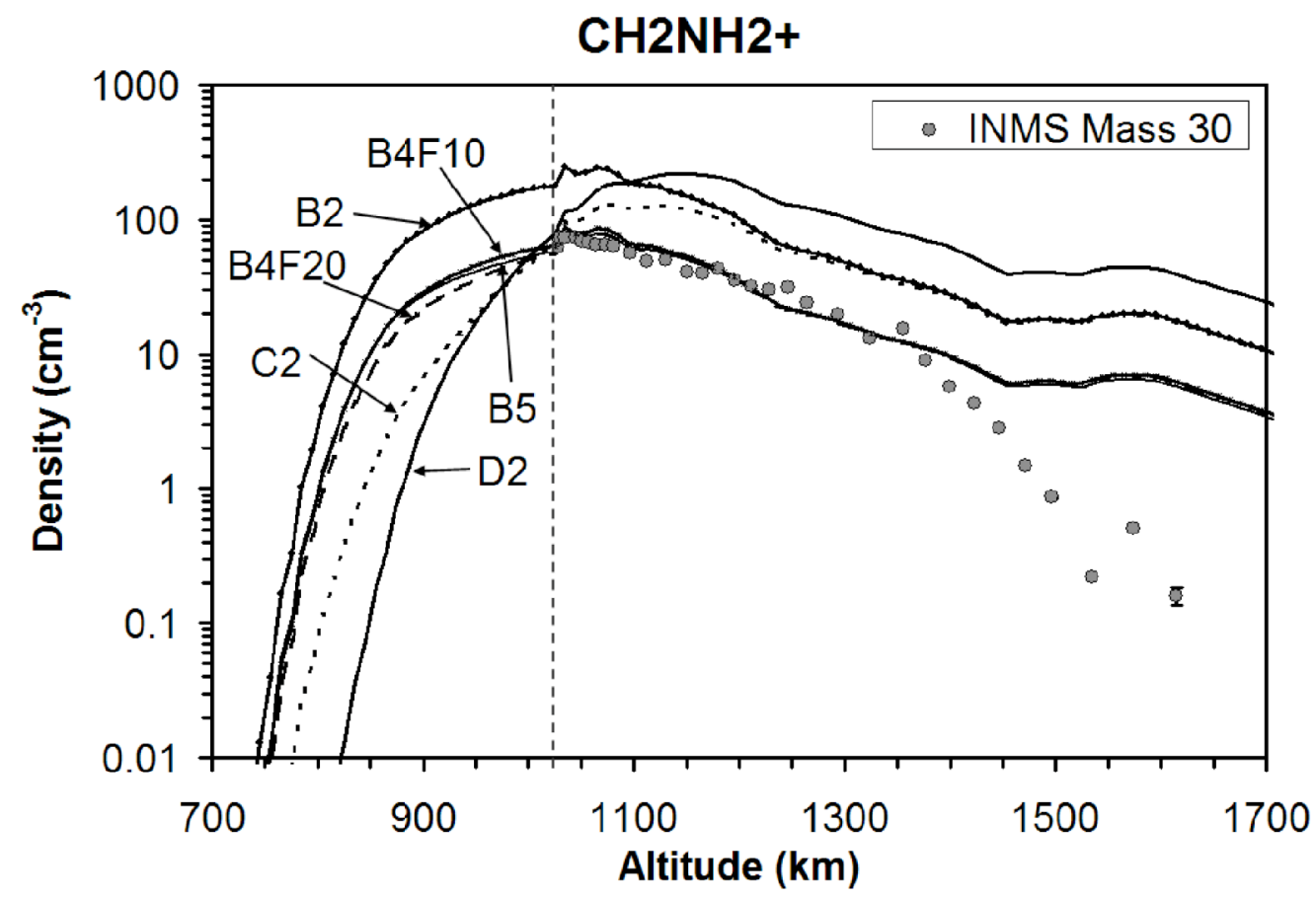

Figure 15. Calculated density versus altitude profile for $\mathrm{CH}_{2} \mathrm{NH}_{2}{ }^{+}$for several model cases (different labeled lines). Also shown are the $\mathrm{m}=30$ densities measured by the INMS on T5. A couple of one sigma statistical error bars are shown. 


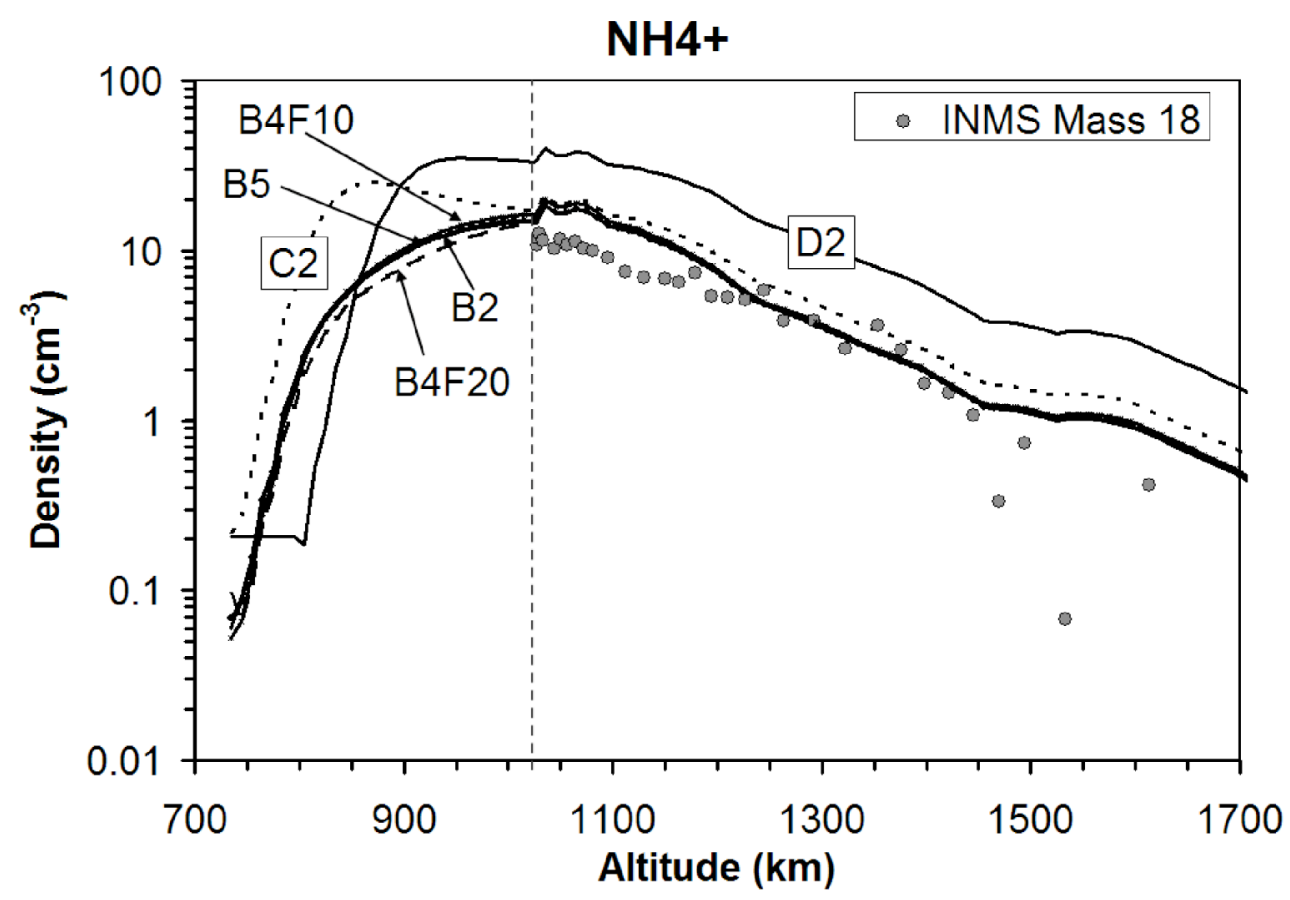

Figure 16. Calculated density versus altitude profile for $\mathrm{NH}_{4}^{+}$for several model cases (different labeled lines). Also shown are the $\mathrm{m}=18$ densities measured by the INMS on T5.

the minor neutral abundances are only identical for the $\mathrm{C} 2$ case. Note that a similar data-model spectrum comparison for $\mathrm{C} 2$ actually has better agreement for $\mathrm{HCNH}^{+}$than the agreement shown in Figure 17 but worse agreement for $\mathrm{C}_{2} \mathrm{H}_{5}{ }^{+}$. More details on the ionospheric chemistry can be found in the Vuitton et al. papers and also in De La Haye et al. (2008a).

What has been learned from the comparison of the INMS ion composition with the several model cases shown in this paper? First, reproducing the overall large-scale altitude variations in ion densities requires that the models have the correct minor neutral composition (e.g., HCN, $\left.\mathrm{C}_{2} \mathrm{H}_{2}, \mathrm{C}_{2} \mathrm{H}_{4}, ..\right)$ and the associated ion-neutral chemistry. All the models shown in this paper meet this qualification. Second, the models show great variability in the factors of 2 to 3 range and depend on the details of the minor neutral composition. The details of the minor ion composition can be exploited to further understand minor neutral composition, as discussed by Vuitton et al. $(2006,2007)$ but this is outside the scope of the current paper. Third, the total ion density (or electron density) profile is not sensitive to the details of the minor ion or neutral composition.

All the above results were for T5 conditions but some model runs were also carried out for T21 conditions. As described earlier, magnetospheric electron fluxes measured by the CAPS ELS (and, hence, the ion production rates in the ionosphere - Figure 5) were smaller for T21 than for T5. Calculated and measured electron densities are both shown in Figure 18. The spacecraft potential during T21 was rather large (exceeding negative $2 \mathrm{~V}$ ), which necessitated a large (and uncertain) INMS transmission correction (Kasprzak et al., in preparation). 


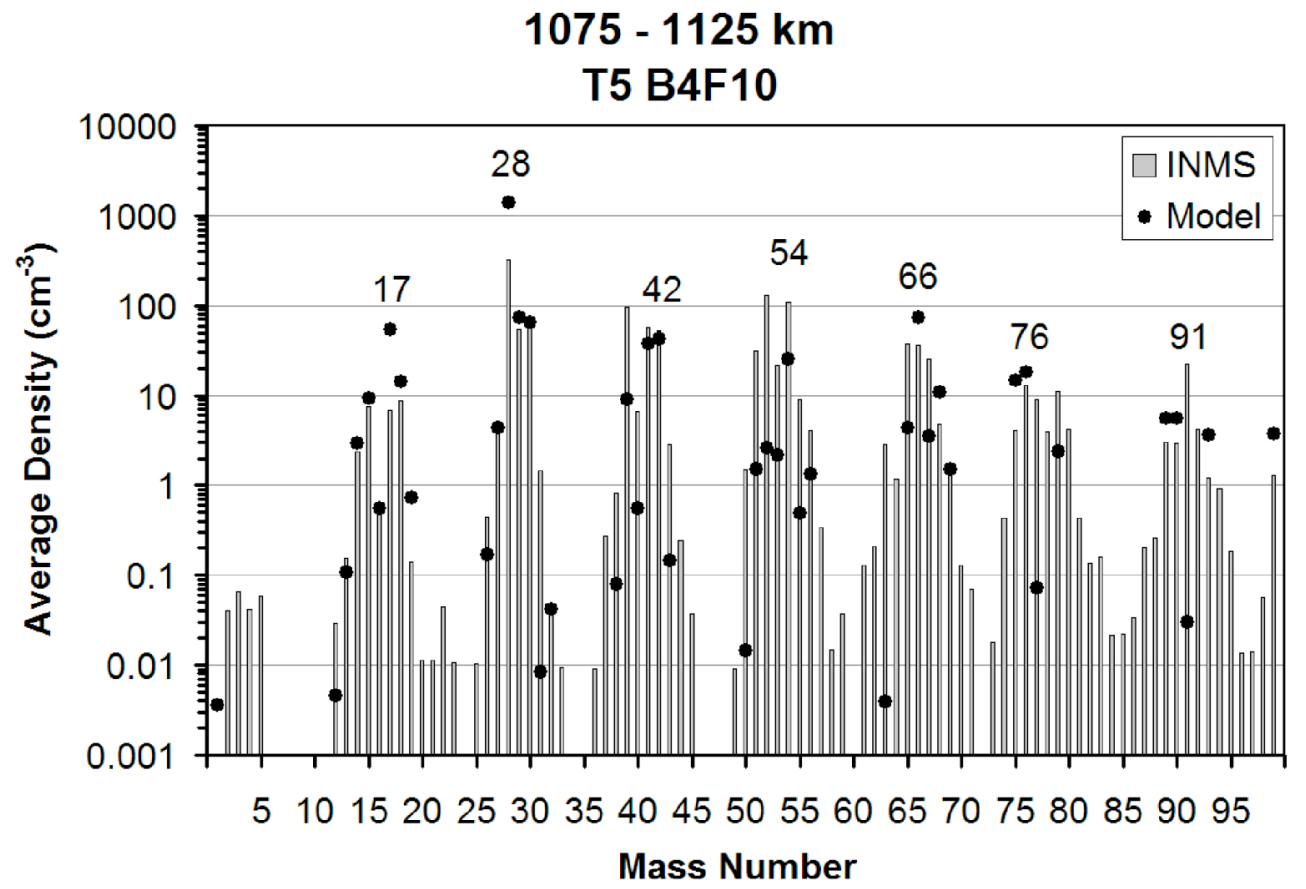

Figure 17. A mass spectrum calculated for the T5 B4 case for an altitude of $1100 \mathrm{~km}$ is shown along with a spectrum measured by the INMS at this altitude.

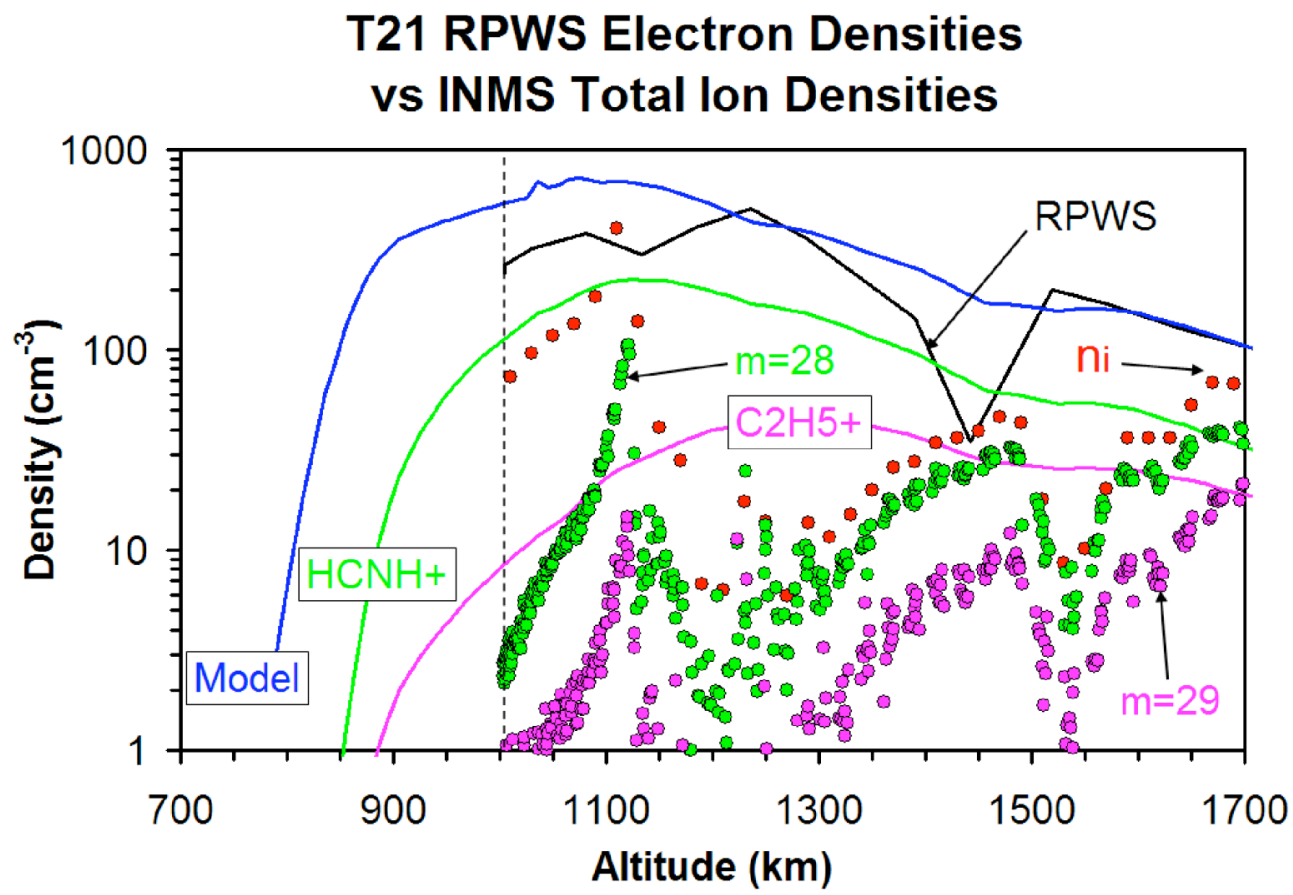

Figure 18. Some measured (INMS) and calculated ion density profiles for $\mathrm{HCNH}^{+}$and $\mathrm{T} 21$ are shown. Also shown are the electron density profiles from RPWS/LP. Note that the spacecraft potential was large for T21 and the corrections for its effects are also large. 
However, the relative ion composition measured by the INMS should be reasonably accurate. The electron densities measured by the RPWS/LP (not subject to the same spacecraft potential effects as INMS) for T21 are clearly about a factor of 4 less than the T5 densities. This is consistent with lower ion production rates for T21 than for T5 and is consistent with the lower magnetospheric electron fluxes observed by the CAPS ELS for T21. Note that in order to obtain data-model agreement, the incident CAPS electron fluxes must again be reduced by a factor of about 2.5-10, just as for the T5 case. Figure 18 also shows $\mathrm{HCNH}^{+}$INMS density measurements and model results.

All the ion density profiles produced by the model vary smoothly with altitude because the calculated ion production rate profiles did not exhibit much altitude variation. The measured electron density profiles (and total ion density profiles) as well as many of the individual ion density profiles are essentially smooth $\left(\mathrm{HCNH}^{+}\right.$, or $\left.\mathrm{CH}_{2} \mathrm{NH}_{2}{ }^{+}, \ldots\right)$, but many other ion species $\left(\mathrm{CH}_{3}{ }^{+}, \mathrm{CH}_{5}{ }^{+}, \mathrm{C}_{2} \mathrm{H}_{5}{ }^{+}, \ldots\right)$ exhibit significant altitude (or time or horizontal distance along the spacecraft track) variations. An examination of the chemical lifetimes (Figure 6) indicates that "smooth profile" species have longer chemical lifetimes and structured species have shorter chemical lifetimes (R. Yelle, October 2006 DPS). The small-scale structure will be discussed in more detail in the next section.

\section{Small-scale variations in the T5 ionosphere}

In this paper we have displayed ion densities as functions of altitude, although Figure 7 also has a time-scale. Cravens et al. (2006) displayed the T5 INMS densities versus spacecraft time and solar zenith angle. In fact, altitude, time, and horizontal location (partially characterized by solar zenith angle) all vary together and are "confounded" variables. The larger-scale structure of the ion densities probably does primarily depend on processes organized by altitude (as has been assumed throughout this paper), but this might not be appropriate for small-scale structure. For example, $\mathrm{CH}_{5}{ }^{+}$(or $\mathrm{C}_{2} \mathrm{H}_{5}{ }^{+}$) has a local density maximum and a minimum at altitudes of 1140 $\mathrm{km}$ and $1220 \mathrm{~km}$, respectively, giving an altitude separation of about $100 \mathrm{~km}$. These altitudes correspond to spacecraft times with respect to closest approach of about $155 \mathrm{~s}$ and $205 \mathrm{~s}$, respectively. The temporal separation of the maxima and minima is about $50 \mathrm{~s}$, corresponding to a distance along the spacecraft track (this is largely "horizontal") of about $300 \mathrm{~km}$ using a spacecraft speed of $6 \mathrm{~km} / \mathrm{s}$. Other small-scale variations are also evident in the outbound T5 ion density data. Note that chemically longer-lived ion species do not exhibit much small-scale structure (e.g., $\mathrm{CH}_{2} \mathrm{NH}_{2}^{+}$) or do so only to a lesser extent (e.g., $\mathrm{HNCH}^{+}$). Recall that the ionosphere is chemically controlled in this $1200 \mathrm{~km}$ region.

Ion production rate profiles calculated by Agren et al. (2007) for the precipitation of monoenergetic incident electrons exhibit altitude widths far exceeding $100 \mathrm{~km}$, which leads us to conclude that altitude/time structures in the observed densities cannot be explained by discrete energy structures in the incident magnetospheric fluxes. In any case, the energy spectra measured by CAPS ELS outside Titan display a broad range of energies (see Figures 1 and 2). By process of elimination, it seems that small-scale ionospheric density structures should be associated with temporal or horizontal (i.e., different magnetic flux tubes) variations in the incident magnetospheric electrons rather than being altitude structures. 
As discussed earlier, primary electrons as they travel down field lines lose energy via inelastic collisions with the neutral atmosphere. The electrons also experience some scattering due to elastic collisions. Secondary electrons are created via impact ionization of atmospheric neutrals. Lower energy (few eV) secondary electrons lose energy primarily via vibrational excitation of $\mathrm{N}_{2}$ and $\mathrm{CH}_{4}$. Secondary electrons are evident in the CAPS ELS color spectrograph (Figure 1) for times when Cassini was within the ionosphere (e.g., near CA). A quick examination of this spectrograph also suggests the presence of some short temporal variations in the secondary electron fluxes. Figure 19 shows both the CAPS ELS count rate for $4.06 \mathrm{eV}$ electrons and the $\mathrm{CH}_{5}{ }^{+}$density measured by INMS plotted versus time. Recall that $\mathrm{CH}_{5}{ }^{+}$is an "almost" primary ion species whose abundance almost directly relates to the production rate of $\mathrm{CH}_{4}{ }^{+}$. The CAPS ELS $4 \mathrm{eV}$ electron count rate and the $\mathrm{CH}_{5}^{+}$density track each other quite well. A similar result (not shown) was obtained for $\mathrm{CH}_{3}{ }^{+}$, an ion species whose density almost directly relates to the $\mathrm{N}_{2}^{+}$production rate.

Figure 19 strongly suggests that the incident electron flux is different for different horizontal locations which are in turn associated with different magnetic flux tubes. However, the density profiles of chemically longer-lived species do not exhibit the small-scale structure that the primary species do, which would have been the case if the electron flux at the top of each flux tube persisted at the same level for a very long time. This suggests that the incident electron fluxes not only differ from flux tube to flux tube, but that the incident electron flux on each magnetic flux tube also has some intrinsic time variation.

Figure 19 also indicates that the secondary electron flux seen at the spacecraft increases overall by a factor of 4 or so from closest approach to a time of $\approx 300 \mathrm{~s}$ after CA. Superimposed on this trend was the "periodicity" mentioned earlier, and in particular a $50 \%$ increase and decrease for times of about 150 to $250 \mathrm{~s}$. For altitudes below about $1400 \mathrm{~km}$, where the mean free path of low energy electrons is less than 100-200 km (i.e., the electrons are local), the secondary electron flux should be approximately independent of the neutral density and be proportional to the primary ( $100 \mathrm{eV}-$ several $\mathrm{keV}$ energies $)$ electron flux. The ion production rate depends on both the $\mathrm{N}_{2}$ density and the primary electron flux. Figure 19 thus indicates that the primary electron flux is about 3 times greater for the flux tubes near $300 \mathrm{~s}$ than for flux tubes near CA. Combining that deduction with the T5 geometry shown by Agren et al. (2007), it seems possible that the flux tubes near the spacecraft location at CA had resided longer in Titan's ionosphere than the flux tubes encountered near $300 \mathrm{~s}$ because these flux tubes are deeper in the atmosphere than the other flux tubes.

\section{Ionospheric dynamics}

The interaction of Saturn's partially co-rotating magnetospheric plasma with Titan is quite complex due to the combination of solar and magnetospheric ionization inputs, due to the typically submagnetosonic, yet super-Alfvenic, upstream flow, due to the presence of multiple ion species, and due to the large upstream ion gyroradii (cf. Hartle et al. 1982; 2006; Ledvina and Cravens 1998; Ma et al. 2007; Backes et al. 2005; Modolo et al. 2007; and many other references). The nominal ram direction of the magnetospheric flow during the outbound portion of the T5 encounter was on the nightside (see the schematic in Agren et al. 2007). The measured magnetic field strength was $\approx 5-10 \mathrm{nT}$ in the ionosphere, and the field was oriented at an angle of $\approx 45^{\circ}$ from the horizontal, even deep within the ionosphere. Global dynamical models of the 
T5 CAPS ELS and INMS

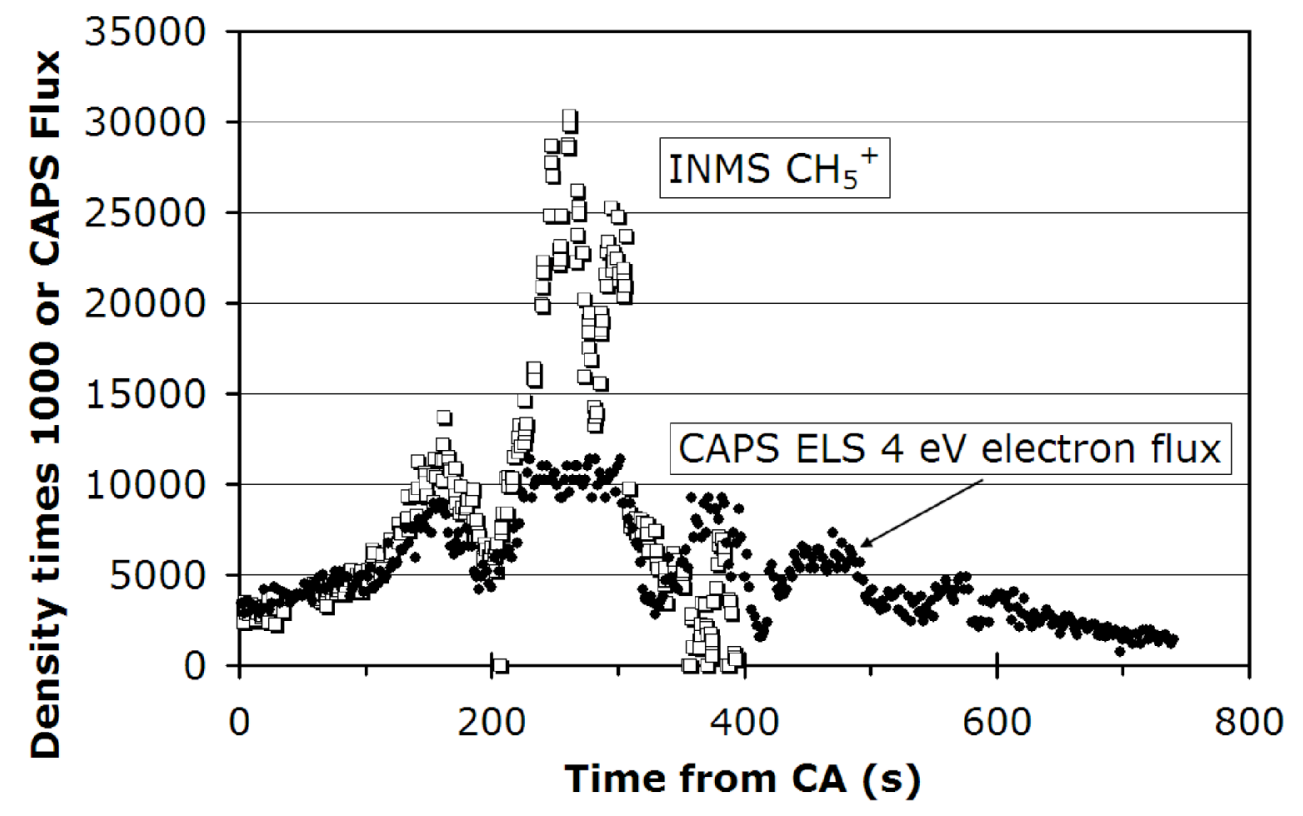

Figure 19. The CAPS ELS electron flux (actually count rate) for $4.06 \mathrm{eV}$ and the $\mathrm{CH}_{5}{ }^{+}$(actually $\mathrm{m}=17$ ) densities measured by INMS are plotted versus time for the outbound portion of the T5 Cassini encounter with Titan.

interaction (i.e., global MHD or hybrid models) for T5 have not been published to our knowledge. However, modeling of other Titan encounters (Ma et al. 2007; T9; Ta) suggests that the magnetic field should be highly draped in the ramside ionosphere (and hence be almost horizontal) at least on the dayside, whereas the field observed at T5 definitely had a significant radial component.

A full consideration of the plasma dynamics during T5 is beyond the scope of the current paper, but in this section we present some simple estimates of ionospheric plasma transport times in order to put the chemical lifetimes (Figure 6) into context. We start by assessing the terms in a simple single-fluid MHD momentum equation (i.e., equation of motion) appropriate for the ionosphere. The Eulerian form of the single-fluid MHD equation can be written as (cf. Cravens 1997):

$$
\rho\left[\frac{\partial \mathbf{u}}{\partial \mathrm{t}}+\mathbf{u} \cdot \nabla \mathbf{u}\right]=-\nabla \mathrm{p}+\mathbf{J} \times \mathbf{B}+\rho \mathbf{g}-\rho \bar{v}\left(\mathbf{u}-\mathbf{u}_{\mathrm{n}}\right)-\mathrm{P}_{\mathrm{i}} \mathrm{m}_{\mathrm{i}}\left(\mathbf{u}-\mathbf{u}_{\mathrm{n}}\right)
$$

where $\rho=n_{i} m_{i}$ is the mass density, $n_{i}=n_{e}$ is the total plasma density, $m_{i}$ is the average ion mass, $\mathbf{u}$ is the bulk flow velocity and $\mathbf{u}_{n}$ is the neutral flow velocity, $p_{i}$ and $p_{e}$ are ion and electron thermal pressures, $p=p_{e}+p_{i}$ is the total thermal pressure, $\mathbf{B}$ is the magnetic field vector, $P_{i}$ is the ion production rate, $\mathbf{g}$ is the acceleration due to gravity, and $v$ is the ion-neutral momentum transfer collision frequency. $\mathbf{J}$ is the current density. 
Equation (8) is rearranged in order to obtain estimates of the plasma flow speed (u) as a function of altitude. The plasma flow within the atmosphere should normally be slow enough for the inertial terms to be neglected (i.e., left-hand side of equation), and the curvature/tension force from the $\mathbf{J} \mathbf{X} \mathbf{B}$ term has been thrown out. We also neglect the mass-loading term (i.e., the $P_{i}$ term on the right-hand side of the equation). Both thermal and magnetic pressure gradients are estimated as pressures divided by length scales of $\mathrm{L}_{p}$ or $\mathrm{L}_{\mathrm{B}}$, respectively. Estimates of "typical" vertical or horizontal scale-length scales will be introduced later. We further convert the square of the magnetic field divided by the plasma mass density to an Alfven speed, $V_{A}$, and similarly convert the thermal pressure term to a sound speed, $\mathrm{V}_{\mathrm{s}}$. Solving for a "diffusion-like" plasma flow speed (cf. Schunk and Nagy 2000; Cravens 1997), we find:

$$
u \approx\left\{\left[V_{A}^{2} / L_{B} \pm V_{s}^{2} / L_{p} \pm g\right]\right\} / v
$$

where the signs depend on the details of the interaction. The ion-neutral collision frequency is given by $v=\mathrm{k}_{\text {in }} \mathrm{n}_{\mathrm{n}}$ where $\mathrm{n}_{\mathrm{n}}$ is the total neutral density and $\mathrm{k}_{\mathrm{in}} \approx 10^{-9} \mathrm{~cm}^{3} \mathrm{~s}^{-1}$ is the collision coefficient (we actually used the sum of the collision frequencies for molecular nitrogen and methane with appropriate coefficients as given by Keller et al. 1994). Rough estimates of the flow speed magnitude at different altitudes were obtained by estimating each of the terms with available Cassini magnetic field and plasma data for T5. We adopted electron densities and temperatures measured by the RPWS Langmuir probe (Agren et al. 2007), the average ion mass from the INMS (Cravens et al. 2006), and the magnetic field strength from the magnetometer experiment (e.g., Backes et al. 2005; Agren et al. 2007), as well as the neutral densities discussed earlier.

A reasonable estimate, probably on the high side, for the flow speed can be obtained if the magnetic and thermal pressure gradient terms act together and if we use length-scale estimates on the low side. We adopt $\mathrm{L}_{\mathrm{p}} \approx \mathrm{L}_{\mathrm{B}} \approx 100 \mathrm{~km}$ as a "minimum" scale length (see the INMS data figures). The RPWS/LP experiment observed 150-350 km scale-lengths in the transportcontrolled topside ionosphere (see Wahlund et al. 2005, Agren et al. 2007). For these vertical flow speed estimates, we let the pressure gradient terms be opposed by the gravitational term, which turns out to be rather unimportant in any case for a $100 \mathrm{~km}$ length scale. The transport time scale is the length scale divided by the flow speed: $\tau \approx \mathrm{L} / \mathrm{u}$. Note that the time expression can also be expressed in terms of an ambipolar diffusion coefficient $\mathrm{D}_{\mathrm{ambi}}$; that is, $\tau \approx \mathrm{L}^{2} / \mathrm{D}_{\mathrm{ambi}}$ (cf. Schunk and Nagy 2000).

Similarly, we estimated "minimum" horizontal flow speeds versus altitude as well as the associated transport times, by adopting horizontal length scales of $\mathrm{L}_{\mathrm{p}} \approx \mathrm{L}_{\mathrm{B}} \approx 500 \mathrm{~km}$ (corresponding to roughly a $100 \mathrm{~s}$ time interval along the spacecraft track). Both vertical and horizontal transport time constants are shown in Figure 6, together with the chemical lifetimes discussed earlier. The "actual" transport times are likely to be somewhat larger than these "minimum" estimates. The transport times decrease with increasing altitude because the ionneutral collision frequency decreases with altitude. These estimates are only appropriate in the ionosphere where ion-neutral collisions play an important role in the momentum balance. A more self-consistent and careful analysis of ionospheric transport processes is certainly required, but this is outside the scope of the current paper.

Figure 6 indicates that chemical processes should dominate over transport processes for altitudes less than about $1400-1500 \mathrm{~km}$ and thus control the distribution of almost all ion 
species (Ma et al. 2006). For some chemically short-lived species, transport should not become important until altitudes well above $1500 \mathrm{~km}$.

We know from studies of the solar wind interaction with non-magnetic bodies like Venus and comets (Luhmann et al. 1997; Cravens et al. 1997; Nagy and Cravens 2002) that magnetic flux tubes convected into the atmosphere and ionosphere move with the relatively slow ionospheric plasma. The ends of the field lines, however, continue to move with the rapidly flowing external plasma such that the field lines are highly draped (and largely horizontal) in the upper atmospheres of non-magnetic bodies. Measurements at Venus, Mars, and comets support this expectation (Luhmann et al. 1997). Both Voyager and Cassini measurements of plasma and field properties near Titan combined with models (cf. review by Neubauer 1984; Backes et al. 2005; Ma et al. 2006, 2007; Ledvina and Cravens 1998; and many other references) clearly demonstrate that Saturn's magnetic field strongly drapes around Titan, although the details of this interaction are different from the Venus and cometary cases. Another consequence of a strong interaction of external plasma with a non-magnetic body is that magnetic field lines can be imbedded in the ionosphere (i.e., due to induced currents) with long residence times.

The interaction situation for T5, in which the ram flow is "opposed" by a nightside ionosphere with rather low densities, seems to have some features that differ from a dayside-ram case. The Cassini magnetometer data indicates that the magnetic field has a significant radial component, yet the estimated ion flow speeds deep within ionosphere are quite low (less than a few $\mathrm{m} / \mathrm{s}$ at $1100 \mathrm{~km}$ using Figure 6 transport times), implying significant field line draping (i.e., mainly horizontal fields). Perhaps the bulk electron flow is not tightly tied to the bulk ion flow (i.e., due to electrical currents). That is, perhaps "Hall" effects are especially important in the nightside ionosphere. Ma et al. (2007) showed that Hall and regular MHD simulations gave different results in Titan's magnetotail for T9 conditions. Note that magnetic flux tubes are tied to the electron flow rather than the ion flow, at least as long as the magnetic Reynolds number stays larger than unity. But Hall effects could be important and affect magnetic flux transport (and flux tube "hang up" times in the ionosphere) for sufficiently large current densities, carried by a relatively low density plasma. Simple estimates for the T5 ionosphere support this conjecture. For $\mathrm{z} \approx 1100 \mathrm{~km}$, electron flow speeds of $\approx 200 \mathrm{~m} / \mathrm{s}$ are needed to carry the electrical currents that generate a $5 \mathrm{nT}$ field variation over a length-scale of $100-200 \mathrm{~km}$. The horizontal convection time for a distance of about $1000 \mathrm{~km}$ and $200 \mathrm{~m} / \mathrm{s}$ is $\approx 1$ hour, which is much less than the horizontal ion convection time shown in Figure 6 at this altitude. Detailed plasma simulations are needed to shed more light on this scenario and on flux tube transport. Also note that the magnetic Reynolds number becomes comparable to, or less than, unity, at a low enough altitudes due to Ohmic resistivity. The magnetic field is then able to "diffuse" so that field lines are not tied to either the electron or the ion gases (cf. Cravens 1997). Using Cassini T5 data we estimate that this transition altitude is at about $1100 \mathrm{~km}$ for T5.

\section{Discussion}

The structure of Titan's nightside ionosphere evidently does not have a single simple explanation for all its features. The overall large-scale trends of the measured ion densities between altitudes of $1027 \mathrm{~km}$ and about $1500 \mathrm{~km}$ appear to be mainly altitude-related features that can be explained by: (1) ion production rates (and their altitude dependence) due to precipitation of suprathermal electrons with an incident spectrum like that observed by the CAPS 
ELS instrument in the nearby magnetosphere of Saturn (albeit with a roughly factor of 2 - 10 reduction), and (2) chemical losses associated with ion-neutral chemical reactions and/or dissociative recombination reactions with altitude-dependencies that are associated with the vertical distributions of many neutral species (i.e., major species such as $\mathrm{N}_{2}$ and $\mathrm{CH}_{4}$, as well as minor species such as $\mathrm{HCN}, \mathrm{C}_{2} \mathrm{H}_{2}, \mathrm{NH}_{3}, \ldots$ ). For altitudes above about $1400-1500 \mathrm{~km}$, an examination of time constants indicates that transport as well as chemistry starts to control the ionospheric structure (see Ledvina and Cravens 1998; Ma et al. 2007; Agren et al. 2007).

The smaller-scale structure (unlike most of the larger-scale trends) evident in chemically short-lived ion species profiles appears to be horizontal or temporal structures. The correlation of the densities of "primary" ion species with secondary electron fluxes observed by CAPS strongly suggests that the small-scale variations are related to differences in the incident suprathermal electron fluxes coming from the magnetosphere at different locations/times across the nightside of Titan. Given that we adopted a factor of $2.5-5$ electron flux reduction for the overall structure, this suggests that at some locations the flux reduction factor should be either greater or less than this by another factor of 2 or so. However, it also seems that the incident electron flux at the "top" of each magnetic flux tube cannot be entirely steady, or all ion species (chemically short-lived and long-lived) would exhibit the same small-scale variations, yet species like $\mathrm{HCNH}+$ have much smoother profiles than species like $\mathrm{CH}_{5}{ }^{+}$. The incident magnetospheric fluxes must both vary from flux tube to flux tube and must also have some "intrinsic" temporal variation with time scales greater than the chemical lifetime of species like $\mathrm{CH}_{5}{ }^{+}$yet less than the lifetime of species like $\mathrm{NH}_{4}{ }^{+}$or $\mathrm{HCNH}^{+}$. An examination of Figure 6 suggests that an "intrinsic" flux time scale for the incident magnetospheric electrons of roughly $1000 \mathrm{~s}$ might do the job for the $1000-1350 \mathrm{~km}$ region.

What is the explanation for the temporal (or horizontal) variations in the incident magnetospheric electron flux? What is responsible for the factor of 2.5 - 10 reduction in the required incident electron fluxes relative to unperturbed outer magnetospheric values? Answering these questions requires a detailed understanding of how Saturn's magnetic field and the outer magnetosphere interact with Titan, and in particular, how suprathermal electrons participate in this process. Such an understanding does not yet exist but results presented in this paper can perhaps provide some insight.

Electrons with $\mathrm{keV}$ or less energies are tied to magnetic field lines (gyroradii of $\approx 10-20 \mathrm{~km}$ for $5-10 \mathrm{nT}$ magnetic fields) for altitudes above about $900 \mathrm{~km}$. Below this altitude the electron-neutral collision frequency exceeds the gyrofrequency and electrons become "unmagnetized." Magnetic flux tubes pushed into Titan's atmosphere by the interaction with the external flow act as conduits for the transport/precipitation of magnetospheric electrons. On the other hand, energetic magnetospheric ions are not very sensitive to the magnetic field topology near Titan (cf. Ledvina et al. 2005; Cravens et al. 2008). Suprathermal electrons moving along field lines that thread deep enough into the atmosphere lose energy via collisional excitation and ionization of neutrals, so that the suprathermal electron fluxes are attenuated. Some fraction of the incident electrons are also scattered back out of the atmosphere due to elastic collisions and lower energy electrons (secondary electrons for the nightside and solar-produced photoelectrons on the dayside) escape from Titan's atmosphere out into Saturn's magnetosphere.

Electrons in Saturn's magnetosphere are trapped by Saturn's approximately dipole magnetic field (with stretching in the plasmasheet, etc., as described by the Cassini MAG team Dougherty et al. 2005), bouncing between mirror points closer to the planet. A magnetic flux tube has a finite electron content, and if such a flux tube becomes attached to Titan's atmosphere, 
then the whole tube should gradually become depleted with a time scale of the bounce period (for electrons of a given energy) within Saturn's magnetic field, unless processes such as crossfield diffusion can replenish the flux tube over the same time-scale. Gan et al. (1993) investigated this scenario using a two-stream electron interaction model for Titan (Gan et al. 1992). Gan et al. carried out a series of 2-stream calculations in which the downward electron flux at the upper boundary was set equal to the calculated upward flux at earlier times with a time delay equal to the electron bounce time at the relevant electron speed/energy. Figure 20 shows a schematic of Saturnian magnetic field lines being draped around Titan. The travel time to the mirror point and back to Titan is $\approx 720 \mathrm{~s}$ for $100 \mathrm{eV}$ electrons and is about $240 \mathrm{~s}$ for $1 \mathrm{keV}$ electrons. Parabolic field lines (within Titan's ionosphere) were assumed, and the apex was moved radially inward with a convection speed that varied linearly with radial distance. Gan et al. demonstrated that $1 \mathrm{keV}$ electron fluxes take about $500 \mathrm{~s}$ to attenuate a factor of 10 and 100 $\mathrm{eV}$ fluxes take about 1000-1500 s. The lower energy electron fluxes (tens of eV) in the Gan et al. simulation actually increased with time due to photoelectron production within the sunlit Titan atmosphere, but this is not applicable to our nightside case.

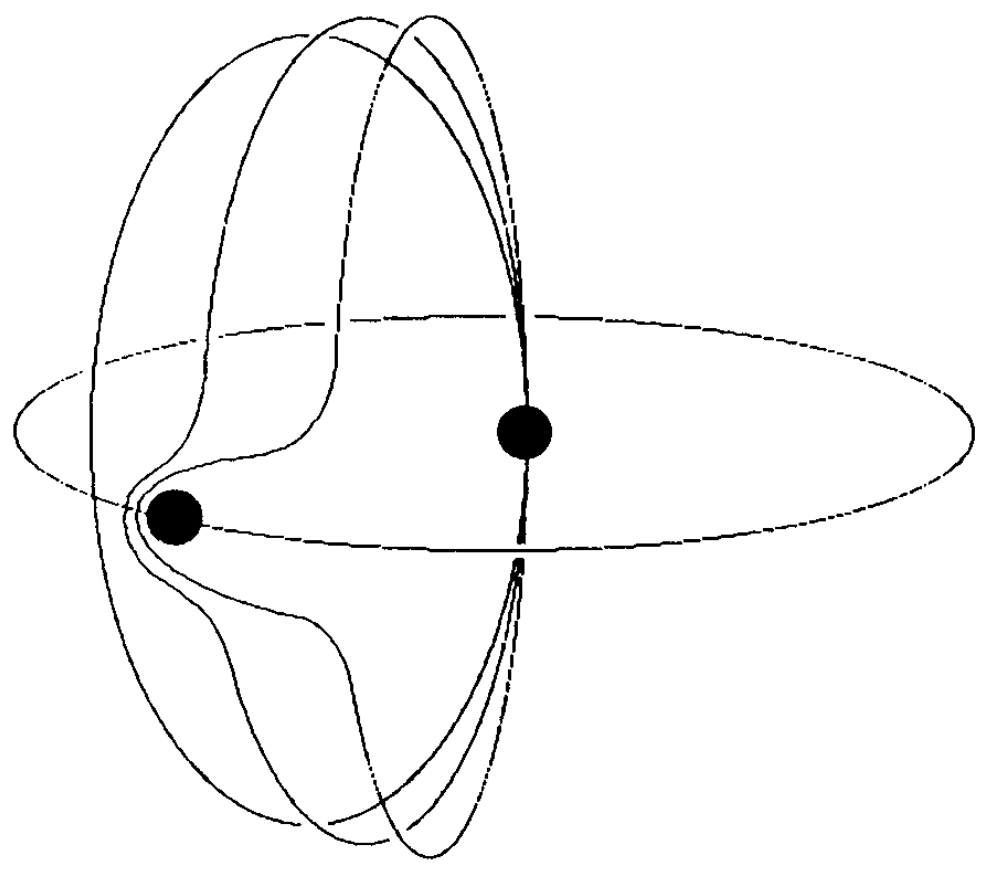

Figure 20. A schematic of Saturnian magnetic field lines being caught up in Titan. From Gan and Cravens (1993).

Gan et al. (1993) adopted rather arbitrary assumptions about flux tube convection through the atmosphere, but qualitatively such flux tube depletion must be taking place. As discussed earlier, INMS data (and the associated model comparisons) seems to indicate that the primary electron flux varies from magnetic flux tube to flux tube, with perhaps the near-CA region being associated with the oldest and most depleted flux tubes. The intrinsic temporal variation due to 
depletion on a given flux tube are supported by the small scale variations seen by INMS in primary ion species but not long-lived species. In fact, it seems surprising that the electron flux depletions for magnetic tubes "hung up" in Titan's ionosphere do not greatly exceed the factors of 2.5 - 10 we found with our data-model comparisons using the CAPS ELS inputs. There are several possible explanations:

(1) Electrons diffuse across magnetic field lines and replenish the electron content of a magnetic flux tube attached to Titan on time scales of about $600 \mathrm{~s}$. (2) The flux tube moves through Titan's atmosphere more quickly than one might expect and is "hung up" for times less than $600 \mathrm{~s}$ (this would require tube speeds in the atmosphere of $\approx 1 \mathrm{R}_{\mathrm{T}} / 600 \mathrm{~s}$ or $4 \mathrm{~km} / \mathrm{s}$, which is an extremely large velocity (note that $100 \mathrm{~m} / \mathrm{s}$ or much less would be expected from the dynamics for altitudes below $1200 \mathrm{~km}$ or so). (3) The backscattered electron flux (see Figure 2) might be much larger than our model predicts so that the electron content in a flux tube can last for several bounce periods (although this would also reduce the flux that actually makes it into the atmosphere). (4) For the long-lived chemical species, some plasma might be flowing from the dayside and help support larger densities than the "immediate" ion production rates would imply (this idea is discussed more in the next paragraph), but this would not help with the shortlived species or with the atmospheric suprathermal electron model-data comparisons (i.e., Figure 19).

We used the time-dependent version of our ionospheric model to investigate how the ionosphere responds to time-varying primary ion production rates. We present just one case here for an altitude of $1200 \mathrm{~km}$. The initial conditions are from the photochemical model (factor of 2.5 depleted production rates and case B4), and then the time-dependent version of the model is run for another $5000 \mathrm{~s}$ with the same ion production rates. At $\mathrm{t}=5000 \mathrm{~s}$ the primary ion production rates are gradually reduced (exponentially) with a time constant of $600 \mathrm{~s}$. At a time of $3000 \mathrm{~s}$ after the exponential decrease is initiated, constant ion production rates are again turned on but with a factor of 25 reduction factor (rather than the original 2.5 factor). Figure 21 shows the time histories of $\mathrm{CH}_{5}^{+}, \mathrm{C}_{2} \mathrm{H}_{5}^{+}, \mathrm{HCNH}^{+}, \mathrm{NH}_{4}^{+}$, and the electron density from this timedependent model. Clearly, the short-lived species $\left(\mathrm{CH}_{5}^{+}\right.$and $\left.\mathrm{C}_{2} \mathrm{H}_{5}{ }^{+}\right)$respond quickly to changes in the primary production rate, whereas species like $\mathrm{NH}_{4}^{+}$show long lag times.

\section{Conclusions}

Model-data comparisons presented in this paper suggest that the overall, large-scale structure can largely be organized in terms of altitude and that the density profile of a given ion species depends on: (1) the distribution of neutral densities for both major $\left(\mathrm{N}_{2}\right.$ and $\left.\mathrm{CH}_{4}\right)$ and minor ( $\mathrm{HCN}, \mathrm{C}_{2} \mathrm{H}_{2}, \ldots$ ) neutral species, and (2) the altitude-dependent primary ion production rates (e.g., for $\mathrm{N}_{2}{ }^{+}, \mathrm{N}+, \mathrm{CH}_{4}{ }^{+}, \mathrm{CH}_{3}{ }^{+} \ldots$.) that result from impact ionization by electrons precipitating from Saturn's magnetosphere. Success was obtained for both T5 and T21 for ion production rates consistent with electron energy spectra measured by the Cassini CAPS-ELS instrument in the nearby magnetosphere, but the incident electron fluxes had to be reduced by a factor of about 2.5 to 10 (the larger reduction being for the lowest altitudes near $1027 \mathrm{~km}$ ). A factor of $\approx 8$ was needed to obtain good agreement between the theoretical suprathermal electron fluxes at 1200 $\mathrm{km}$ the ones measured by the CAPS ELS at that altitude. 


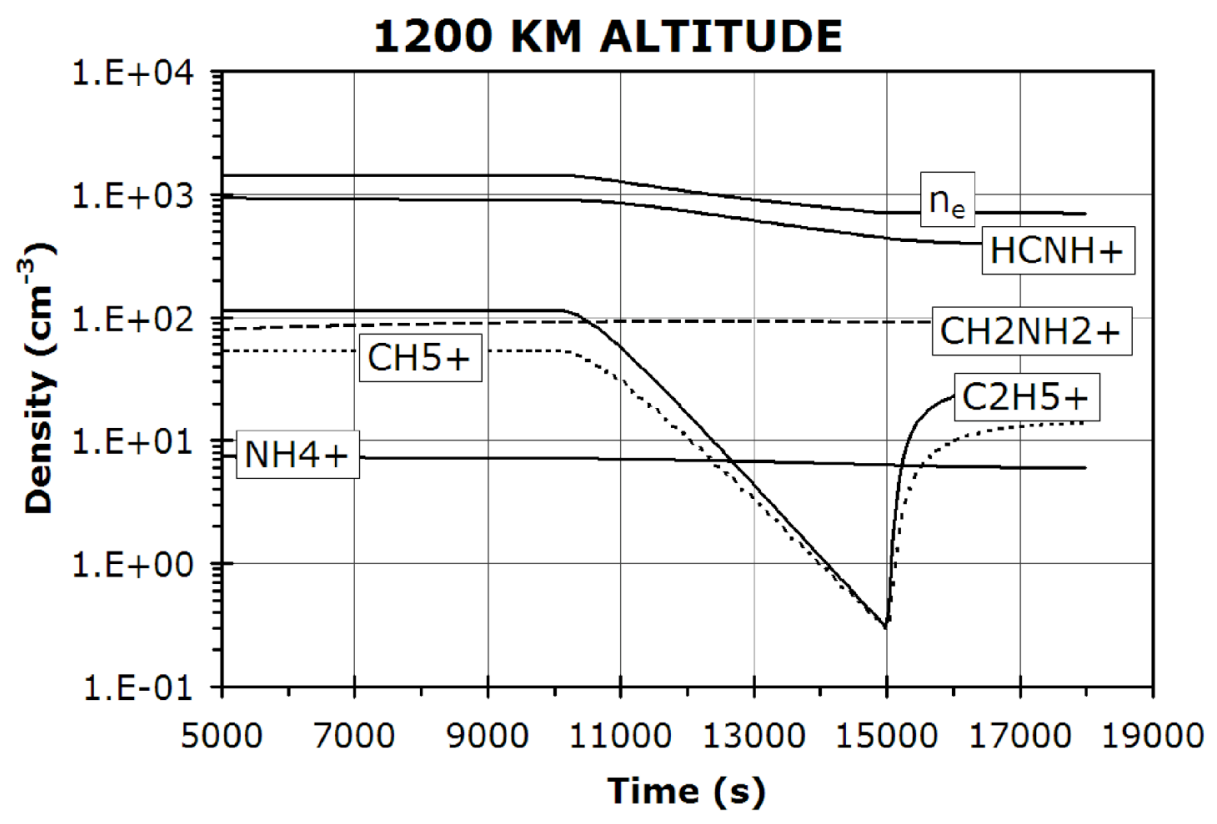

Figure 21. Densities versus time from the time-dependent ionospheric model for a few species, for an altitude of $1200 \mathrm{~km}$, and for T5 conditions. The primary ion production rates for time less than $8000 \mathrm{~s}$ were those used in the photochemical model (i.e., consistent with CAPS magnetospheric electron fluxes divided by a factor of 2.5), but with an exponential decay (with time constant $=600 \mathrm{~s}$ ) between a time of $8000 \mathrm{~s}$ and $15000 \mathrm{~s}$. At a time of $15000 \mathrm{~s}$ the "standard" production rates were re-introduced but with an extra factor of 10 reduction factor.

We now make a few summary comments on the ion composition results of the paper. Several model cases with different minor neutral compositions were considered in this paper. We learned that the ion density structure observed on the nightside of Titan by INMS can be explained for larger length/altitude scales within factors of $2-3$ accuracy. But achieving better accuracy requires a careful assessment of the minor neutral composition and knowledge of the ion-neutral chemistry, which is beyond the scope of the current paper. Two other limitations of the current study are that we did not present results for mass numbers greater than the 100 Dalton upper limit of the INMS, and we did not include negative ions. Some ionospheric models have included some positive ion species with mass numbers well beyond 100 Daltons (e.g., Keller et al. 1998; Vuitton et al. 2007) and the Cassini CAPS instrument measured (as yet unpublished) ion mass spectra beyond 100 Daltons, but our understanding of this high-mass chemistry is still poor. Similarly, the Cassini CAPS ELS detector observed negative ions in the lower Titan ionosphere (Coates et al. 2007a), but our understanding of the associated chemistry is almost nonexistent (cf. Waite et al. 2007).

Smaller-scale (i.e., $\Delta \mathrm{z} \approx 100-150 \mathrm{~km}$ or time-scales of $100 \mathrm{~s}$ or so) structures evident in chemically short-lived ion species (but not long-lived species) require for their explanation ion production rates (and incident electron fluxes) that vary by factors of 2 or so from location to location (and hence from magnetic flux tube to magnetic flux tube) on Titan's nightside. This was supported by the correlations shown in the paper between low energy electron fluxes measured by the CAPS-ELS instrument and the measured density of $\mathrm{CH}_{5}{ }^{+}$. The different 
temporal responses of short and long-lived ion species can be perhaps be used as a "clock" to study the temporal history of magnetic flux tubes caught up in Titan's ionosphere. A time constant of a few hundred seconds appears to be required to explain the ionospheric structure for T5 (intermediate between the chemical lifetimes of the primary and terminal ion species in Figure 6). And this time-scale of $600 \mathrm{~s}$ is approximately a bounce period in Saturn's magnetosphere for few hundred $\mathrm{eV}$ electrons.

Acknowledgments. Support from the NASA Cassini project (grant NFP45280 via subcontract from Southwest Research Institute) is acknowledged. Model development at the University of Kansas was also supported by NASA Planetary Atmospheres Grant NNX07AF47G. RY acknowledges support through NASA grant NAG5-11078. The Swedish National Space Board (SNSB) supports the RPWS LP instrument onboard Cassini. AC and HW thank STFC (UK) for financial support of ELS and NASA/JPL contract 1243218 for financial support of the CAPS investigation.

\section{References}

Agren, K., 15 colleagues 2007. On magnetospheric electron impact ionisation and dynamics in Titan's ram-side and polar ionosphere - a Cassini case study. Ann. Geophys. 25, 2359-2369.

Anicich, V. G., McEwan, M. J. 1997. Ion-molecule chemistry in Titan's ionosphere. Planet. Space Sci. 45, 897-921.

Anicich, V. G., Wilson, P., McEwan, M. J. 2004. A SIFT ion-molecule study of some reactions in Titan's atmosphere. Reactions of $\mathrm{N}^{+}, \mathrm{N}_{2}{ }^{+}$, and $\mathrm{HCN}^{+}$with $\mathrm{CH} 4, \mathrm{C}_{2} \mathrm{H}_{2}$, and $\mathrm{C}_{2} \mathrm{H}_{4}$. J. Am. Soc. Mass Spectrum 15, 1148.

Atreya, S. K. 1986. Atmospheres and ionospheres of the outer planets and their satellites. Springer-Verlag, New York.

Backes, H., Neubauer, F. M., Dougherty, M. K., Achilleos, H., Andre, N., Arridge, C. S., Bertucci, C., Jones, G. H., Khurana, K. K. 2005. Titan's magnetic field signature during the first Cassini encounter. Science 308, 992-995.

Banaskiewicz, M., Lara, L. M., Rodrigo, R., Lopez-Moreno, J. J., Molina-Cuberos, G. J. 2000. A coupled model of Titan's atmosphere and ionosphere. Icarus 147, 386-404.

Bird, M. K., Dutta-Roy, R., Asmar, S. W., Rebold, T. A. 1997. Detection of Titan's ionosphere from Voyager 1 radio occultation observations. Icarus, 130, 426-436.

Carrasco, N., Dutuit, O., Thissen, R., Banaszkiewicz, M., Pernot, P. 2007. Uncertainty analysis of bimolecular reactions in Titan ionosphere chemistry model. Planet. Space Sci. 55, 141-157.

Coates, A. J., Crary, F. J., Lewis, G. R., Young, D. T., Waite, J. H., Jr. 2007a. Discovery of heavy negative ions in Titan's ionosphere, Geophys. Res. Lett. 34, L22103-L22107, doi:10.1029/2007GL030978.

Coates, A. J., Crary, F. J., Young, D. T., Szego, K., Arridge, C. S., Bebesi, Z., Sittler, E. C., Jr. 2007b. Ionospheric electrons in Titan's tail: Plasma structure during the Cassini T9 encounter, Geophys. Res. Lett. 34. L24505-L24519, doi:10.1029/2007GL030919.

Cravens, T. E. 1997. Physics of Solar System Plasmas, Cambridge Univ. Press.

Cravens, T. E., Shinagawa, H., Luhmann, J. G., 1997. Magnetohydrodynamic processes: Magnetic fields in the ionosphere of Venus. In: Bougher, S. W., Hunten, D. M., Phillips, R. J. (Eds), Venus II - Geology, Geophysics, Atmosphere, and Solar Wind Environment, pp. 6193, Univ. of Arizona Press, Tucson. 
Cravens, T. E., Lindgren, C. J., Ledvina, S. A. 1998. A two-dimensional multifluid MHD model of Titan's plasma environment. Planet. Space Sci. 46, 1193.

Cravens, T. E., Vann, J., Clark, J., Yu, J., Keller, C. N., Brull, C. 2004. The ionosphere of Titan: An updated theoretical model. Adv. Space Res. 33, 212, doi:10.1016/J.asr.2003.02.012.

Cravens, T. E., 15 colleagues 2005. Titan's ionosphere: Model comparisons with Cassini Ta Data. Geophys. Res. Lett. 32, no. 12, L12108, doi: 10.1029/2005GL023249.

Cravens, T. E., 15 colleagues 2006. The composition of Titan's ionosphere. Geophys. Res. Lett. 33, L07105, doi:10.1029/2005GL025575.

Cravens, T. E., Robertson, I. P., Ledvina, S. A., Mitchell, D., Krimigis, S. M., Waite, J. H. Jr. 2008. Energetic ion precipitation at Titan. Geophys. Res. Lett. 35, 03103, doi:10.1029/2007GL032451.

Dougherty, M. K., 17 colleagues, 2005. Cassini magnetometer observations during Saturn orbit insertion. Science 307, 1226.

De La Haye, V., 12 colleagues 2007a. Cassini ion and neutral mass spectrometer data in Titan's upper atmosphere and exosphere: Observation of a suprathermal corona. J. Geophys. Res. 112, A07,309, doi:10.1029/2006JA012222.

De La Haye, V., Waite, J. H., Jr, Cravens, T. E., Nagy, A. F., Yelle, R. V., Johnson, R. E., Lebonnois, S., Robertson, I. P. 2007b. Titan's corona: The contribution of exothermic chemistry. Icarus 191, 236-250, doi:10.1016/j.icarus.2007.04.031.

De La Haye, V., Waite, J. H., Jr., Cravens, T. E., Robertson, I. P., Lebonnois, S. 2008a. Coupled ion and neutral rotating model of Titan's upper atmosphere. Submitted to Icarus.

De La Haye, V., Waite, J. H., Jr., Cravens, T. E., Bougher, S. W., Robertson, I. P., Bell, J. M. 2008b. Heating Titan's upper atmosphere. Submitted to J. Geophys. Res.

Fox, J. L., Yelle, R. V. 1997. Hydrocarbon ions in the ionosphere of Titan, Geophys. Res. Lett. 24, 2179-2182.

Galand, M., Lilensten, J., Toublanc, D., and Maurice, S. 1999. The ionosphere of Titan: Ideal diurnal and nocturnal cases. Icarus 104, 92.

Galand, M. et al. 2006. Electron temperature of Titan's sunlit ionosphere. Geophys. Res. Lett. 33, L21101, doi:10.1029/2006GL027488.

Gan, L., Keller, C. N., Cravens, T. E. 1992. Electrons in the ionosphere of Titan. J. Geophys. Res. 97, 12136.

Gan, L., Cravens, T. E., Keller, C. N. 1993. A time-dependent model of suprathermal electrons at Titan. In: Gombosi, T. I. (Ed.) Plasma Environments of Non-Magnetic Planets, vol. 4, p. 171, Elsevier.

Hartle, R. E., Sittler, E. C., Jr., Ogilvie, K., Scudder, J. D., Lazarus, A. J., Atreya, S. K. 1982. Titan's ion exosphere observed from Voyager 1, J. Geophys. Res. 87, 1383.

Hartle, R. E. et al. 2006. Initial interpretation of Titan plasma interaction as observed by the Cassini plasma spectrometer: Comparisons with Voyager 1. Planet. Space Sci. 54, 12111224.

Kabin, K., Gombosi, T. I., DeZeeuw, D. L., Powell, K. G., Israelevich, P. L. 1999. Interaction of the Saturnian magnetosphere with Titan. J. Geophys. Res. 104, 2451-2458.

Kasprzak, W. K., et al., 1996. Cassini orbiter ion and neutral mass spectrometer. Proc. SPIE 2803, 129.

Keller, C. N., Cravens, T. E. 1994. One dimensional multispecies hydrodynamic models of the wakeside ionosphere of Titan. J. Geophys. Res. 99, 6527. 
Keller, C. N., Cravens, T. E., Gan, L. 1992. A model of the ionosphere of Titan. J. Geophys. Res. 97, 12117-12135.

Keller, C. N., Cravens, T. E., Gan, L. 1994. One dimensional multispecies magnetohydrodynamic models of the ramside ionosphere of Titan. J. Geophys. Res. 99, 6511 ,

Keller, C. N., Anicich, V. G., Cravens, T. E. 1998. Model of Titan's ionosphere with detailed hydrocarbon chemistry. Planet. Space Sci. 46, 1157-1174.

Kliore, A. J., 12 colleagues, 2008. First results from the Cassini radio occultations of the Titan ionosphere. J. Geophys. Res., in press, doi:10.1029/2007 JA012965.

Krimigis, S. M., 31 colleagues, 2005. Dynamics of Saturn's magnetosphere from MIMI during Saturn's orbital insertion. Science 307, 1270-1273.

Ledvina, S. A., Cravens, T. E. 1998. A three-dimensional MHD model of plasma flow around Titan. Planet. Space Sci. 46, 1175.

Ledvina, S. A., Cravens, T. E., Kecskemety, K. 2005. Ion distributions in Saturn's magnetosphere near Titan. J. Geophys. Res. 110, A6, A06211, doi:10.1029/2004JA010771.

Lilensten, J., Simon, C., Witasse, O., Dutuit, O., Thissen, R., Alcarez, C. 2005a. A fast comparison of the diurnal secondary ion production in the ionosphere of Titan. Icarus 174, 285-288.

Lilenfeld, J., Witasse, O., Simon, C., Soldi-Lose, H., Dutuit, O., Thissen, R., Alcaraz, C. $2005 b$. Prediction of a N2++ layer in the upper atmosphere of Titan. Geophys. Res. Lett. 32, L03203, doi:10.1029/2004GL021432.

Luhmann, J. G., Brecht, S. H., Spreiter, J. R., Stahara, S. S., Steinholfson, R. S., Nagy, A. F. 1997. Global models of the solar wind interaction with Venus. In: Bougher, S. W., Hunten, D. M., Phillips, R. J. (Eds.), Venus II, Geology, Geophysics, Atmosphere, and Solar Wind Environment, Univ. of Arizona Press, Tucson, pp. 33-60.

Ma, Y.-J., Nagy, A. F., Cravens, T. E., Sokolov, I. U., Hansen, K. C., Wahlund, J.-E., Crary, F. J., Coates, A. J., and Dougherty, M. K. 2006. Comparisons between MHD model calculations and observations of Cassini flybys of Titan. J. Geophys. Res. 111, A05207, doi:10.1029/2005JA011481.

Ma, Y.-J., Nagy, A. F., Cravens, T. E., Sokolov, I. G., Clark, J., Hansen, K. C. 2004. 3-D global model prediction for the first close flyby of Titan by Cassini. Geophys. Res. Lett. 31, L22803, doi 10.1029/2004GL02145.

Ma, Y.-J. et al. 2007. 3D global multispecies Hall-MHD simulation of the Cassini T9 flyby. Geophys. Res. Lett. 34, L24S10.

McClain, J. L., Poterya, V., Molek, C. D., Babcock, L. M., Adams, N. G. 2004 . Flowing afterglow studies of the temperature dependencies for dissociative recombination of $\mathrm{O}_{2}^{+}$, $\mathrm{CH}_{5}^{+}, \mathrm{C}_{2} \mathrm{H}_{5}^{+}$, and $\mathrm{C}_{6} \mathrm{H}_{7}^{+}$with electrons. J. Phys. Chem. A, 108, 6706-6708.

Modolo, R., Wahlund, J.-E., Bostrom, R., Canu, P., Kurth, W. S., Gurnett, D., Lewis, G. R., Coates, A. J. 2007. Far plasma wake of Titan from the RPWS observations: A case study. Geophys. Res. Lett. 34, L24S04, doi:10.1029/2007GL030482.

Molina-Cuberos, G. J., et al. 2001. Ionosphere layer induced by meteoric ionization in Titan's atmosphere. Planet. Space Sci., 49, 143.

Nagy, A. F., Banks, P. M. 1970. Photoelectron fluxes in the ionosphere, J. Geophys. Res. 75, 6260-6270. 
Nagy, A. F., Cravens, T. E. 2002. Solar system ionospheres. In: Mendillo, M., Nagy, A., Waite, J. (Eds.), Atmospheres in the Solar System: Comparative Aeronomy, Geophys. Monograph 130, pp. 39-54, AGU, Washington, DC.

Neubauer, F. M., Gurnett, D. A., Scudder, J. D., Hartle, R. E. 1984. Titan's magnetospheric interaction. In: Gehrels, T., Matthews, M. D. (Eds.), Saturn, pp. 760-787, Univ. of Arizona Press, Tucson.

Rymes, M., 13 colleagues, 2007. Electron sources in Saturn's magnetosphere, J. Geophys. Res. 112, A02201, doi:10.1029/2006JA012017.

Schardt, A. W., Bohannon, K. W., Lepping, R. P., Carbary, J. F., Eviatar, A., Siscoe, G. L. 1984. The outer magnetosphere. In: Gehrels, T., Matthews, J. W. (Eds.) Saturn, pp. 416-459, Univ. of Arizona Press, Tucson.

Schunk, R. W., Nagy, A. F. 2000. Ionospheres. Cambridge Univ. Press, Cambridge.

Toublanc, D., Parisot, J. P., Brillet, J., Gautier, D., Raulin, F., Mckay, C. P. 1995. Photochemical modeling of Titan's atmosphere. Icarus 113, 2-26.

Vervack, R. J. J., Sandel, B. R., Strobel, D. F. 2004. New perspectives on Titan's upper atmosphere from a reanalysis of the Voyager 1 UVS solar occultations. Icarus 170, 91-112.

Vuitton, V., Yelle, R. V., Anicich, V. G. 2006. The nitrogen chemistry of Titan's upper atmosphere revealed. Astrophys. J. 647, L175-L178.

Vuitton, V., Yelle, R. V., McEwan, M. 2007. Ion chemistry and N-containing molecules in Titan's upper atmosphere. Icarus 191, 722-742.

Wahlund, J.-E, et al., 2005. Cassini measurements of cold plasma in the ionosphere of Titan. Science 308, 986-989.

Waite, J. H., Jr., et al., 2004. The Cassini ion and neutral mass spectrometer (INMS) investigation. Space Science Rev. 114(1), 113.

Waite, J. H., Jr., Cravens, T. E., Ip, W.-H., Kasprzak, W. T., Luhmann, J. G., McNutt, R. L., Niemann, H. B., Yelle, R. B., Meuller-Wodarg, I., Ledvina, S. A., Scherer, S. 2005. Oxygen ions observed near Saturn's A ring. Science 307, 1260-1262.

Waite, Jr., J. H., 21 colleagues, 2005. Ion Neutral Mass Spectrometer (INMS) results from the first flyby of Titan. Science 308, 982-986.

Waite, J. H., Jr., Young, D. T., Cravens, T. E., Coates, A. J., Crary, F. J., Magee, B., Westlake, J. 2007. The process of tholin formation in Titan's upper atmosphere. Science 316, 870-875, doi:10.1126/science.1139727, 2007.

Wilson, E. H., Atreya, S. K. 2004. Current state of modeling the photochemistry of Titan's mutually dependent atmosphere and ionosphere. J. Geophys. Res. 109, E06002, doi: 10.1029/2003JE002181.

Young D. T., 42 colleagues, 2005. Composition and dynamics of plasma in Saturn's magnetosphere. Science 307, 1262-1266. 